\title{
The /H/ Phenomenon: Overgeneralised Or Confused? The Nigerian Yoruba-English Speakers As A Case Study
}

\author{
Oluwabukola Omolara Bamidele \\ bukolabamidele12@gmail.com
}

Follow this and additional works at: https://researchrepository.wvu.edu/etd

Part of the African Languages and Societies Commons

\footnotetext{
Recommended Citation

Bamidele, Oluwabukola Omolara, "The /H/ Phenomenon: Overgeneralised Or Confused? The Nigerian Yoruba-English Speakers As A Case Study" (2019). Graduate Theses, Dissertations, and Problem Reports. 3846.

https://researchrepository.wvu.edu/etd/3846

This Thesis is protected by copyright and/or related rights. It has been brought to you by the The Research Repository @ WVU with permission from the rights-holder(s). You are free to use this Thesis in any way that is permitted by the copyright and related rights legislation that applies to your use. For other uses you must obtain permission from the rights-holder(s) directly, unless additional rights are indicated by a Creative Commons license in the record and/ or on the work itself. This Thesis has been accepted for inclusion in WVU Graduate Theses, Dissertations, and Problem Reports collection by an authorized administrator of The Research Repository @ WVU. For more information, please contact researchrepository@mail.wvu.edu.
} 
THE /h/ PHENOMENON: OVERGENERALISED OR CONFUSED? THE NIGERIAN YORUBA-ENGLISH SPEAKERS AS A CASE STUDY OLUWABUKOLA OMOLARA BAMIDELE

THESIS SUBMITTED TO THE

DEPARTMENT OF WORLD LANGUAGES, LITERATURE, AND LINGUISTICS AT WEST VIRGINIA UNIVERSITY

IN PARTIAL FULFILLMENT OF THE REQUIREMENTS FOR THE DEGREE OF MASTERS IN LINGUISTICS

JONAH KATZ, PH.D. CHAIR

SANDRA STJEPANOVIC, PH.D.

SERGIO ROBLES PUENTE, PH.D.

DEPARTMENT OF WORLD LANGUAGES, LITERATURE, AND LINGUISTICS

MORGANTOWN, WEST VIRGINIA 2019

KEYWORDS: YORUBA GLOTTAL SOUND AND /h/ DROPPING PHENOMENON COPYRIGHT 2019 BAMIDELE OLUWABUKOLA OMOLARA 


\section{ABSTRACT \\ THE /h/ PHENOMENON: OVERGENERALISED OR CONFUSED? THE NIGERIAN YORUBA-ENGLISH SPEAKERS AS A CASE STUDY \\ OLUWABUKOLA OMOLARA BAMIDELE}

In this thesis, I examined why the Yoruba speakers of the English language have difficulty in pronouncing word-initial glottal fricative in English. /h/ dropping and /h/ insertion is not expected as the Yoruba language supposedly have the glottal fricative in its sound inventory. I gave a brief introduction to Yoruba phonetics, a brief history about the contact between English and Yoruba language, and what other researchers have written about the /h/ dropping and insertion phenomenon.

The research question was why the Yoruba-English speakers delete and insert the glottal fricative at the word-initial position. I started by investigating the nature of the Yoruba glottal sound. The result was that the Yoruba language has four variants of the glottal sound. These variants are not contrastive and as such, they are used interchangeably.

I went further to investigate what the Yoruba speakers pronounce when they pronounce the English /h/. I then compared these pronunciations with the American native speaker's pronunciations. The result from these analyses showed that the Yoruba-English speakers transfer the four variants of the Yoruba glottal sound into English; such that, the native speakers perceive $/ \mathrm{h} /$ insertion or $/ \mathrm{h} /$ dropping depending on the variant used. 


\section{DEDICATION}

This thesis is dedicated to JESUS: the author and finisher of my soul. 


\section{ACKNOWLEDGEMENT}

My foremost gratitude goes to God for giving me life and the grace to complete this thesis. Without You Lord, I am nothing! I would also like to appreciate my Committee chair, Dr. Jonah Katz and the members of my committee, Dr. Sandra Stjepanovic, and Dr. Sergio Robles Puente, for their tremendous help, advice, and guidance.

Special gratitude to my participants: Mr Taoreed Lawal, Mrs Mujidat Adeyemo Lawal, Mrs Bimpe Fasuyi Adeniji, Mrs Mariam Adeyemo, Ms Abimbola Abiodun and Ms Shannon Ballard.

My husband, Prince Aderemi Oyerinde, thanks so much darling for being so understanding and supportive. God bless you the more Ayomi. Gratitude to Nancy Bonovich Smaltz for being so supportive. I appreciate my friends, my colleagues, and Tai' Bamidele's family, thanks so much for your support.

Lastly, my profound gratitude to the Department of World Languages, Literature and Linguistics, and the Intensive English Program (IEP) for the funding provided.

\section{God bless America! God bless Nigeria!}




\section{TABLE OF CONTENT}

CHAPTER ONE: GENERAL BACKGROUND TO THE STUDY 1

The focus of the study 1

Location/ historical background of Yoruba people 2

Yoruba / English contact 2

Genetic classification 3

Sound inventory of Yoruba language 4

$\begin{array}{ll}\text { The motivation for the study } & 6\end{array}$

$\begin{array}{ll}\text { Data collection and data analysis } & 7\end{array}$

$\begin{array}{ll}\text { Organization of the thesis } & 7\end{array}$

$\begin{array}{ll}\text { CHAPTER TWO: LITERATURE REVIEW } & 8\end{array}$

CHAPTER THREE: THE YORUBA GLOTTAL SOUND 12

$\begin{array}{ll}\text { Research Design } & 15\end{array}$

CHAPTER 4: /h/ DROPPING AND INSERTION INTO ENGLISH WORDS 30

CHAPTER 5: SUMMARY AND CONCLUSION 41

$\begin{array}{ll}\text { General summary } & 41\end{array}$

$\begin{array}{ll}\text { Hypotheses versus result } & 42\end{array}$

Conclusion / further research 44

$\begin{array}{ll}\text { References } & 46\end{array}$

$\begin{array}{ll}\text { Appendix } 1 & 49\end{array}$

Appendix 2

Appendix $3 \quad 53$

Appendix 4 


\section{CHAPTER ONE}

\section{GENERAL BACKGROUND TO THE STUDY}

\section{The focus of the study}

This thesis is aimed at describing an aspect of the Nigerian English with focus on the Yoruba-English speakers. The major focus of my analysis will be on $/ \mathrm{h} / \mathrm{dropping}$ and insertion. $/ \mathrm{h} /$ dropping is the deletion of $/ \mathrm{h} /$ sound from words, especially when it occurs at the wordinitial position and $/ \mathrm{h} /$ insertion is the addition of $/ \mathrm{h} / \mathrm{sound}$ at the word-initial position, where the $/ \mathrm{h} /$ sound is not originally present. Examples in English are 1:

1. A) Head /hed/ pronounced as [ed] - deletion

B) Eat /it/ pronounced as [hit] - insertion

The Yoruba language is presumed to have $/ \mathrm{h} /$ in its sound inventory. However, there are different accounts of the realization of this sound. One account stated that the Yoruba $/ \mathrm{h} / \mathrm{is}$ a fricative while the other account stated that the Yoruba $/ \mathrm{h} /$ is a glottal approximant. These controversies will be discussed as it is relevant to this research. The $/ \mathrm{h} /$ sound segment will be investigated to shed light on the reason for the controversy, and to ascertain why the YorubaEnglish speakers drop or insert /h/ in speech when speaking English. This /h/ dropping phenomenon is common with Nigerian Yorubas in comparison with other speakers of the English language in Nigeria (Ugorji 2010). The Investigation into the $/ \mathrm{h} / \mathrm{dropping}$ and insertion phenomenon is the basis for this research which will be done through analysis of recorded words on Praat (Boersma \& Weenink 2018). Concentration will be on the Yoruba speakers therefore, they will be the major participants for data collection. 


\section{Location/ historical background of Yoruba people}

The Nigerian Yoruba speakers are found in south-west Nigeria. They occupy six states, namely; Oyo, Osun, Ondo, Ogun, Lagos, and Ekiti. There are also some communities and towns occupied by the Yoruba people in Kogi and Kwara (Biobaku 1958). This is better illustrated in the Nigerian map below.

Yoruba states are

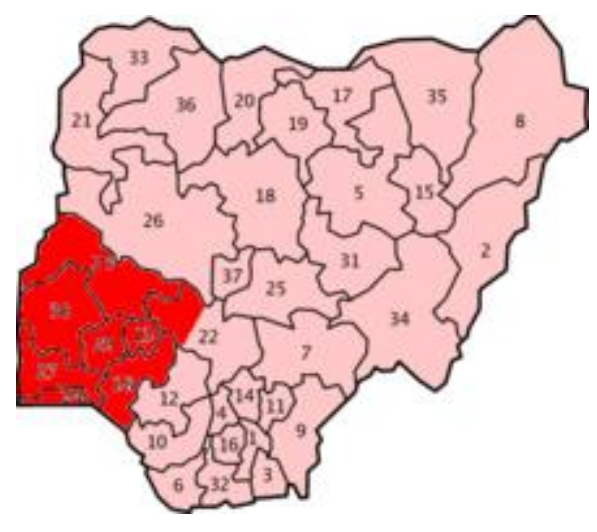

highlighted in the map

The Yoruba people are one of the major tribes in West Africa (Biobaku, 1958). Their population is about twenty-six million in Nigeria alone (Ugorji 2010). The Yoruba tribe were immigrants from a place close to Egypt and had Arab influences in their former homeland. They migrated and settled in the present Ile -Ife in Osun State, Nigeria; leaving a portion of settlements which turned-out to be communities in Togo, Ghana, and the Benin Republic as they progressed to their present destination. Yorubas are also found in Brazil known as the Lucumi people and in Sierra Leone as the Aku people (Biobaku, 1958).

\section{Yoruba / English contact}

According to Dada (2007), in 1821, Yoruba had the first contact with the Europeans during the trade with the Portuguese. Afterward, the missionaries from Britain introduced the English language to the Nigerian Yoruba community by introducing Christianity. This contact brought about Pidgin English. Afterward, Britain decided to colonize present-day Nigeria. During colonization, the British made English the formal language of Nigeria which was 
retained after independence in 1960. Nigeria used English as the lingua-franca until it became the official language and the language of education. This brought about the Yoruba variety of English language in Nigeria. According to Muhammad, Ya'u, Aliyu, and Hassan (2018, pg.11), the Nigerian English was born out of transfer from the first language to the target language which causes interlingual interference. Another factor that influences the learner is that Nigeria is not the target language environment. Based on these submissions from Mohammed et al. (2018), it can be inferred that these errors were transferred from one generation to another.

In the next subsections of this chapter, I will give a brief introduction to the Yoruba language using the genetic classification and sound inventory.

\section{Genetic classification}

Yoruba language (according to the Ethnologue of World Languages), is in the NigerCongo family, Atlantic-Congo sub-family, followed by the Volta-Congo, Benue-Congo, Defoid 17, Yoruboid, and Edekiri group of Languages. This can be better illustrated with the genetic tree. 
Fig 1.1 Yoruba genetic classification

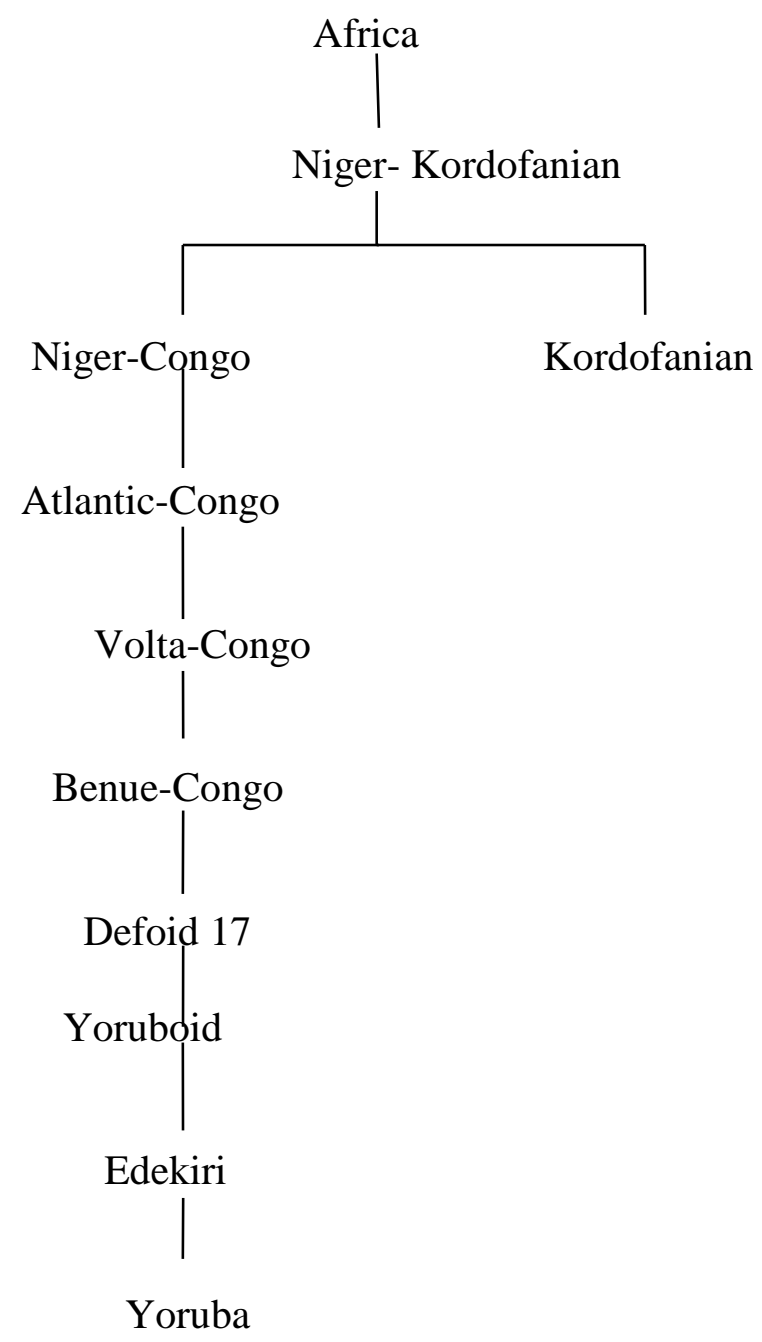

\section{Sound inventory of Yoruba language}

According to Akinlabi (2004), the Yoruba language has seven vowels and eighteen consonants sounds. The seven distinctive vowels are / a e $\varepsilon$ i o $\supset$ u / and eighteen distinctive

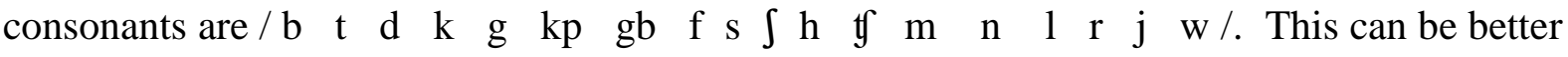
illustrated using the I.P.A. phonetic chart. There are also five nasal vowels /ã $\tilde{\varepsilon} \tilde{1}$ ũ $\tilde{~} /$ 


\section{Vowel chart}

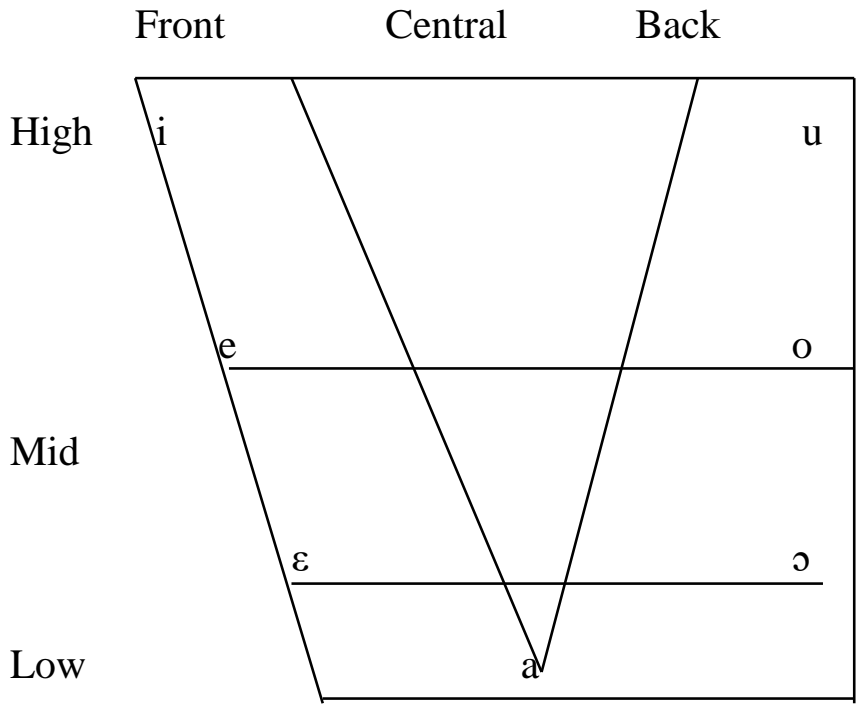

\section{Consonant chart}

\begin{tabular}{|l|l|l|l|l|l|l|l|l|}
\hline $\begin{array}{l}\text { Place } \\
\text { Articulation }\end{array}$ & Bilabial & Labio- & Alveolar & Palato- & Palatal & Velar & $\begin{array}{l}\text { Labial- } \\
\text { Velar }\end{array}$ & Glottal \\
\hline $\begin{array}{l}\text { The Manner of } \\
\text { Articulation }\end{array}$ & $\mathrm{b}$ & & $\mathrm{t} \mathrm{d}$ & & & $\mathrm{k} \quad \mathrm{g}$ & $\mathrm{kp} \mathrm{gb}$ & \\
\hline Fricatives & & $\mathrm{f}$ & $\mathrm{s}$ & $\mathrm{f}$ & & & & $\mathrm{h}$ \\
\hline Affricates & & & & $\mathfrak{t}$ & & & & \\
\hline Nasals & $\mathrm{m}$ & & $\mathrm{n}$ & & & & & \\
\hline Tap & & & $\mathrm{r}$ & & & & & \\
\hline Laterals & & & 1 & & & & & \\
\hline Approximants & & & & & $\mathrm{J}$ & & $\mathrm{W}$ & \\
\hline
\end{tabular}

(Adapted from Oyebade, 1992, pg. 221)

In the next subsections, I will explain the motivation for this research and a brief insight into the data analysis which will be fully explained in subsequent chapters. Lastly, I will explain the organization of the thesis. 


\section{The motivation for the study}

When an individual whose mother tongue is Yoruba speaks English that he or she learned as a second language or acquired as a first language (but in Nigeria), there are differences in the pronunciation of some words compared to the pronunciation of native British or American speakers (see examples 1 and 2 above). This pronunciation makes such words sometimes unintelligible to the native speakers or is perceived as an accent (Banjo, 1975). The question therefore is: Why the difference?

According to Rotimi (2014), the hypothesis is that some sounds are not present in the mother tongue of the Yoruba-English learner; therefore, the learner substitutes such sounds in English with the ones available in his/her native language. This may lead to phonological processes such as devoicing, deletion, insertion, etc. His hypothesis after a further investigation proved to be true. However, the investigation did not include /h/ dropping.

The glottal fricative is a sound that is present in the sound system of Yoruba (Oyebade, 1992). The reason Yoruba speakers delete /h/ while pronouncing an English word with the /h/ sound is a mystery. This is peculiar to this tribe as other major tribes in Nigeria do not do the same (Olaniyi, 2014). This can be further explained with the following excerpt:

'Whereas the Hausas have difficulty in articulating those fricatives, mentioned above, the Yorubas do not but have their own difficult sounds that mark them sociolinguistically as stereotypes. Such include the articulation of the voiceless glottal fricative, $/ \mathrm{h} /$ and the misplacement of $/ \mathrm{f} /$ for $/ \mathrm{v} / \mathrm{and} / \mathrm{s} /$ for $/ \mathrm{J} /$ in speech contexts. (Olaniyi, 2014, pgs. 232-240)'

It is worthy to note at this point that Yoruba is a tonal based language while English is stressed based. Also, Yoruba has an open syllabic system while English has a closed syllabic 
system. It is important to note these differences as Yoruba and English language will be compared in subsequent chapters using mostly prosodic and syllabic features as the basis for comparison.

\section{Data collection and data analysis}

In chapter three and four of this research, I describe a qualitative and quantitative analysis of $/ \mathrm{h} /$ in Yoruba using recordings from Yoruba native speakers. I also analyze $/ \mathrm{h} / \mathrm{in}$ English recordings using the American native speaker's pronunciation. These recordings will be examined under different conditions.

\section{Organization of the thesis}

In this chapter, I have been able to give a general introduction to the Yoruba language through historical background of the language, its contact with English, the genetic and phonetic classification, focus and motivation for the study and a brief insight to how the data would be analysed. In the following chapter, I will give the literature review to the Nigerian variety of English language with emphasis on Yoruba speakers of English. Also, I will indicate my research questions and hypotheses. In the third chapter, I will analyse the Yoruba glottal sound; its peculiarities and characteristics. In the fourth chapter, I will examine the Yoruba glottal sound in comparison to the English glottal sound. I will answer my research questions in this chapter and will examine and analyse my hypotheses. In the last chapter, I will give a general summary, discuss my research result and indicate topics for further research. 


\section{CHAPTER 2}

\section{LITERATURE REVIEW}

According to Gass and Selinker (2008), error analysis is the 'type of linguistic analysis that focuses on the errors learners make'. This means that the spoken language of a learner can be analysed through data collection to ascertain what error(s) the learner makes, why these error(s) occur, where they make this error(s) and the implications.

In the case of Yoruba speakers, they cannot be totally called learners. They are bilinguals only with a different variety of English language. This is because English is the language of education in Nigeria, but Yoruba is their mother tongue. Therefore, Yoruba speakers have been exposed to the English language as children. This also implies that English and Yoruba were acquired simultaneously, although, the variety of English acquired is slightly different from that of native speakers.

Despite this early acquisition, the knowledge of Yoruba language influences that of the English language. According to Banjo (1995), as cited in Ugorji (2010), there are different levels of mother tongue influence on the Nigerian speakers depending on their level of exposure to the English language. He indicated the levels of mother tongue influences as follows:

1. Mother-tongue based: characteristic of semi-educated Nigerians (mostly people with pre-primary school level of education)

2. Influenced by mother tongue: less of mother tongue influence but lacks major phonological distinctions in English (Mostly associated with speakers with primary school education). 
3. Close to Received Pronunciation (RP): characteristics of educated Nigerians (mostly university level education).

4. Indistinguishable from RP: characteristics of highly educated Nigerians (mostly post university level education or those trained specially in English phonetics).

For this research, my participants are in the third strata of Banjo's classification. It is important for this research that my participants attain and remain in this level or strata because people in this level are close to the Received Pronunciation (RP), but have not mastered the pronunciation of some sounds such as the voiceless glottal fricative $/ \mathrm{h} /$ which is the focus of my analysis.

/h/ dropping phenomenon is a common issue. There is also a variety of English with hdropping such as the Cornish people of England (see Wells, 1982, pg. 254). Speakers of some languages have trouble with English /h/, for instance, the French learners of English language who drop and insert /h/ into English words. According to Paradis and LaCharite (2001), in the case of these French learners of English, the glottal fricative is not present in the sound system of their language and as such, they drop the $/ \mathrm{h} /$ sound when pronouncing words that have $/ \mathrm{h} /$. For the French learners, this difficulty comes from the native inventory that doesn't have $/ \mathrm{h} /$. Therefore, the French learner cannot fathom how to articulate the /h/ sound and unconsciously deletes it. According to Paul and Walcir (2008), the French learner inserts the /h/ sound before every word-initial vowel when they eventually learn to pronounce it, thus hyper-correcting and over-generalizing the correction to this error. The submissions from Paradis and LaCharite (2001), and Paul and Walcir (2008) showed that /h/ dropping is a case of negative transfer from languages that don't have $/ \mathrm{h} /$.

Yoruba reputedly does have /h/. According to Oyebade (1992), the Yoruba glottal sound is a glottal fricative and Akinlabi (2004) described the Yoruba /h/ as a glottal approximant. 
Although the Yoruba $/ \mathrm{h} /$ according to Akinlabi is subject to a wide range of phonetic and phonological variation and alternations in different positions, it does not change the fact that this sound is present in the Yoruba sound inventory. Yet, Yoruba speakers seem to have the same trouble with English /h/ as French speakers do. Therefore, the negative transfer account fails, unless the preceding proposals are incorrect. The bone of contention, therefore, is that, if $/ \mathrm{h} /$ is present in the sound inventory of Yoruba language, then, why do Yoruba-English speakers drop and insert /h/ into English words just like the French learners of English language? It is worthy to note here that although the standard Yoruba sound inventory has the glottal sound $/ \mathrm{h} /$, it is not transparent (i.e. a straight forward glottal fricative). Also, Yoruba phonological patterning of $/ \mathrm{h} /$ is very different from English $/ \mathrm{h} /$, and it has more in common phonologically with glides than fricatives.

From the foregoing, the following questions can be deduced.

1. What characterizes the Yoruba $/ \mathrm{h} /$ and how does it differ from the English $/ \mathrm{h} /$.

2. If there is a difference between the Yoruba $/ \mathrm{h} /$ and the English $/ \mathrm{h} /$, could it adequately account for the /h/ dropping and insertion by the Yoruba-English speakers?

Based on the above questions, I came up with the following hypotheses.

1. The Yoruba language does not have the glottal fricative and therefore the Yoruba-English speaker deletes unfamiliar sounds but when they realize this error, they tend to hypercorrect it just like the French-native speakers. If this hypothesis is right, how then do we account for the presumed $/ \mathrm{h} /$ in the Yoruba sound inventory? Could it be that $/ \mathrm{h} /$ in the Yoruba sound inventory is an error or a different sound? This research tries to answer these questions.

2. The second hypothesis is that the Yoruba sound inventory has two glottal sounds. This would indicate that one has been recognized and the other is hidden or has not been 
discovered. If this hypothesis is correct, could it be the reason for the variations between Oyebade and Akinlabi's proposals with respect to /h/? Also, could it be the reason for $/ \mathrm{h} /$ dropping in the English language by Yoruba speakers?

3. The third hypothesis is that, whatever the Yoruba sound notation ' $/ \mathrm{h} /{ }^{\prime}$ is meant to represent is sufficiently distinct from English /h/ in phonological or phonetic terms (or both) that it cannot straightforwardly be adopted as an L1 'model' for L2 English, or that adopting it in this way results in perceived errors.

4. There is a fourth hypothesis. The idea is that the Cornish speakers of English language colonized or had the first contact with the Yoruba people in Nigeria alongside the Portuguese. Thus, the Yoruba-English descends from this native variety with $/ \mathrm{h} / \mathrm{dropping}$ embedded in it. This possibility may not be totally convincing as the Yoruba-English speakers were not the only tribe colonized, but they are the only major ethnic group in Nigeria that has the shibboleth. The other major ethnic groups in Nigeria (Hausa and Igbo) do not have this variation even though they were all simultaneously colonized by Britain (see Olaniyi \& Ekerete, 2013). Therefore, this is unlikely to be a case of inheritance from the British. Although the first contact between the British and the Yoruba speaking part of Nigeria is unclear, this may be an aspect to investigate later in follow-up research to ascertain this possibility or erase this idea altogether.

For this research, however, attention will be given to the first, second and third hypotheses stated earlier. In the following chapter, I will investigate the Yoruba $/ \mathrm{h} /$. 


\section{CHAPTER THREE}

\section{THE YORUBA GLOTTAL SOUND}

Yoruba is an African language that has been well investigated, especially its sound inventory. However, the $/ \mathrm{h} /$ sound has been controversial. This sound is represented as a glottal fricative in some phonetic descriptions, and as a glottal glide in other phonetic descriptions.

Akinlabi (2004, pg. 458) indicated that the /h/ in Yoruba sound system is a glottal approximant although, he noted that the glottal sound $/ \mathrm{h} /$ has been categorized as a glottal fricative in earlier studies. He exemplified the Yoruba glottal approximant using: 'aha' (a calabash or bowl) where the glottal sound was clearly a glide between the two vowels. On the other hand, Oyebade (1992), recognized /h/ as a glottal fricative. In the phonetic description that she proposed, the Yoruba /h/ was clearly stated as a voiceless glottal fricative. This should literarily indicate that the glottal fricative in Yoruba is similar or synonymous to the English glottal fricative. Therefore, there should be no reason for discrepancies. However, this is not the case because the Yoruba-English speakers drop the glottal fricative at the word-initial position and insert the glottal fricative before word-initial vowels in English. Thus, it is important to investigate the nature of the Yoruba glottal sound.

Akinlabi (2004) gave a clearer argument on the nature of /h/ in the Yoruba sound inventory. He explained in his paper (Akinlabi, 1991) that there are three contrastive glides in Yoruba /w/ $/ \mathrm{h} /$ and $/ \mathrm{j} /$ as illustrated in 2 .

2. A) iwa /iwa/ 'character',

B) iya /ija/ 'suffering' and

C) iha /iha/ 'side'. 
He explained that the oral glides /w/ and /j/ and the high vowels $/ \mathrm{i} /$ and $/ \mathrm{u} /$ in Yoruba synchronize when these high vowels are nasalized (he called them homo-organic nasal vowels) to derive $[\mathrm{h}]$. This synchronization occurs when these homo-organic vowels are preceded by the oral glides at the word-medial position. This synchronization will neutralize their place of articulation, thereby, changing the oral glides $/ \mathrm{w} /$ and $/ \mathrm{j} /$ to $[\mathrm{h}]$ which has no place of articulation. e.g.

\section{Owun /owũ/ - [ohũ]}

Eyin /عjĩ/ - [عhĩ]

This means that $/ \mathrm{w} /$ changes to [h] in the word-medial position when it is followed by the nasalized / $\tilde{\mathrm{u}} /$ vowel. Also, /j/ changes to [h] at the word-medial position when it is followed by the nasalized / $\tilde{1} /$ vowel. It is important to note that all glides and approximants are normally voiced and have supra-laryngeal constriction wider than other consonants. However, the [h] realization in Yoruba does not have this supra-laryngeal constriction. Also, $[\mathrm{h}]$ is unspecified for voicing except when it is adjacent to homo-organic vowels which makes its realization to be voiced (though it is basically breathiness or glottal frication).

Akinlabi (1991) further indicated that $/ \mathrm{h} /$ is not the underlying segment in this inter-vocalic position in Yoruba, thereby debasing an alternate account that stated that $/ \mathrm{h} /$ is the underlying segment in this position. He clarified this proposal by consulting thirteen dialects of Yoruba and he found out that the standard variety is the only variety that alternates $/ \mathrm{w} / \mathrm{/} / \mathrm{j} /$ to $[\mathrm{h}]$. In other dialects, the glides $/ \mathrm{w} /$ and $/ \mathrm{j} /$ are either retained or deleted in this position when there is the sequence of this oral glides /w/ or /j/ with the homo-organic nasal vowels / $\tilde{\mathrm{u}} /$ and / $\tilde{\mathrm{i}} /$ respectively. According to Akinlabi (1991), since the other dialects have /w/ and /j/ and do not allow these oral glides to change to [h] before homo-organic vowels, it implies that the oral 
glides/w/ and /j/ are syn-chronic sources for $[\mathrm{h}]$ at the word-medial position in the standard Yoruba variety. He also noted that $[\mathrm{h}]$ is unspecified for voicing and it doesn't need to be specified as it is not contrastive for voicing in this position. He inferred in this analysis that $/ \mathrm{h} /$ as a distinct phoneme in Yoruba is a glide because its allophone [h] can be derived from the synchronization of the oral glides /w/ and /j/ with the homorganic nasal vowels.

To further buttress his point, Akinlabi (1991) examined the case of word-initial $/ \mathrm{h} / \mathrm{He}$ explained that, just like $/ \mathrm{w} /$ and $/ \mathrm{j} /$ are the synchronic sources for $[\mathrm{h}]$ at the word-medial position, /h/ is the synchronic source for $[\mathrm{j}]$ and $[\mathrm{w}]$ at the word-initial position. An example is seen in 4.

4. A) /hu/- changing to [wu] (to grow) and B) /hũ/- to [wũ] (to weave).

Here, he indicated that $/ \mathrm{h} /$ is the underlying segment in the word-initial position i.e. $/ \mathrm{h} / \mathrm{is}$ the syn-chronic source in this position when followed by homorganic nasal vowels. This implies that although there is alternation between $/ \mathrm{h} /$ and $/ \mathrm{w} /, / \mathrm{w} /$ is not the syn-chronic source for $[\mathrm{h}]$ at the word-initial position but $/ \mathrm{h} /$ is the syn-chronic source for [w]. To verify this claim, he tried to use /w/ as the underlying segment e.g.

5. A. /wu/ - *[hu] - (to swell) - this is not allowed in Yoruba, but B is allowed B. /iho/ - [iwo] (horn)

The alternation between /h/-/j/ (with /h/ being the synchronic source for [j]) cannot be tested at the word-initial position because there is no sequence of $* / \mathrm{hi} / \mathrm{i} . \mathrm{e}$. $/ \mathrm{h} /$ followed by the front high vowel /i/ in Yoruba. However, the alternation between /j/-[h] at the word-initial position can be tested with $/ \mathrm{j} /$ being the source of synchronization just as it was tested for $/ \mathrm{w} /$. This is illustrated with example six below.

6. Yi /ji/ - *[hi], 
Yin /jĩ/- *[hĩ] (see Akinlabi, 1991, pgs. 13-25 for more examples).

Here, just like /w/, $/ \mathrm{j} /$ cannot be the source of synchronization for $/ \mathrm{h} / \mathrm{but} / \mathrm{h} /$ is the source for both [w] and [j]. Based on these analyses, he was able to offer an argument that $/ \mathrm{h} / \mathrm{is}$ a glide just like /w/ and /j/ in the Yoruba language.

It is important to clarify that $[\mathrm{h}]$ in Akinlabi (1991) analysis is different from $/ \mathrm{h} / .[\mathrm{h}]$ as described by Akinlabi (1991) is derived from the synchronization that occurs between the glides /w/ and /j/ when they are adjacent to homo-organic vowels / $\tilde{\mathrm{u}} /$ and /î/ respectively at the word-medial position. He used the $[\mathrm{h}]$ analysis as evidence that $/ \mathrm{h} / \mathrm{as}$ a distinctive sound in Yoruba is a glide just like $/ \mathrm{w} /$ and $/ \mathrm{j} /$ instead of the fricative classification given by previous researchers. Below are examples showing $/ \mathrm{h} /$ occurring in the medial position as a free phoneme (i.e. not derived). Examples are seen in 7.

7. A. ahere- /ahere/ -hut

B. Ihamo/ihamo/- seclusion

C. Ahoro /ahoro/ - rabbit

Based on these submissions from Oyebade and Akinlabi, there is a controversy as to how to represent or describe the glottal sound in Yoruba. This study tries to investigate the status of this phoneme by considering the outlined hypotheses in chapter two.

\section{Research design}

Three participants, who speak Yoruba as a mother tongue were interviewed. They all speak standard Yoruba, they all spent their first twenty years in Yoruba speaking communities and they were residents of Ibadan, Ondo, and Lagos respectively. Sixty-two Yoruba words were given to these participants to pronounce (see appendix four for the list of words). These 
pronunciations were recorded, and the $/ \mathrm{h} /$ pronunciations were analysed on Praat (Boersma $\&$ Weenink, 2018).

To identify the characteristics of the Yoruba /h/, the first step was to find out what the Yoruba speakers pronounce when they pronounce words with /h/ in the Yoruba language. This was investigated by identifying the positions of occurrence of $/ \mathrm{h} / \mathrm{in}$ Yoruba. The positions of occurrence include the word-initial position and the word-medial position. The Yoruba language does not allow consonants at the word-final position because it has an open syllable system.

Some of the investigated words in the initial position are:

8. Ho /ho/- shout,

Hun /hũ/- weave,

Han /hã/- screech,

$\mathrm{Ha} / \mathrm{ha} /$ - clumsy etc.

Some of the words in the medial position are:

9. Ehin /عhĩ/- back,

Iho /iho/ - hole,

Ohun /ohũ/- voice,

iha- /iha/ side etc. (see appendix 4 for the full list of words).

The words with $/ \mathrm{h} /$ as the initial phoneme was the first set to be analysed. The first observation was that these words are verbs and exclamations. The Second observation was that; when these words were observed, there was the presence of the glottal sound at the 
beginning. However, the glottal sound was sometimes realized as a glottal stop [?] and at other times a glottal fricative $[\mathrm{h}]$. When the glottal fricative or glottal stop is realized is unclear while listening to the pronunciation in the spectrum? This is an aspect to be further investigated later in this research. The third observation was that the higher and frontier the following vowel, the better the chance of observing the glottal sound. This means that, though the glottal sound was present before the vowels, it was easier to observe the glottal sound before front vowels than before low back vowels. The following images give a clearer illustration.

Fig. $3.1 /$ hẽ̃/

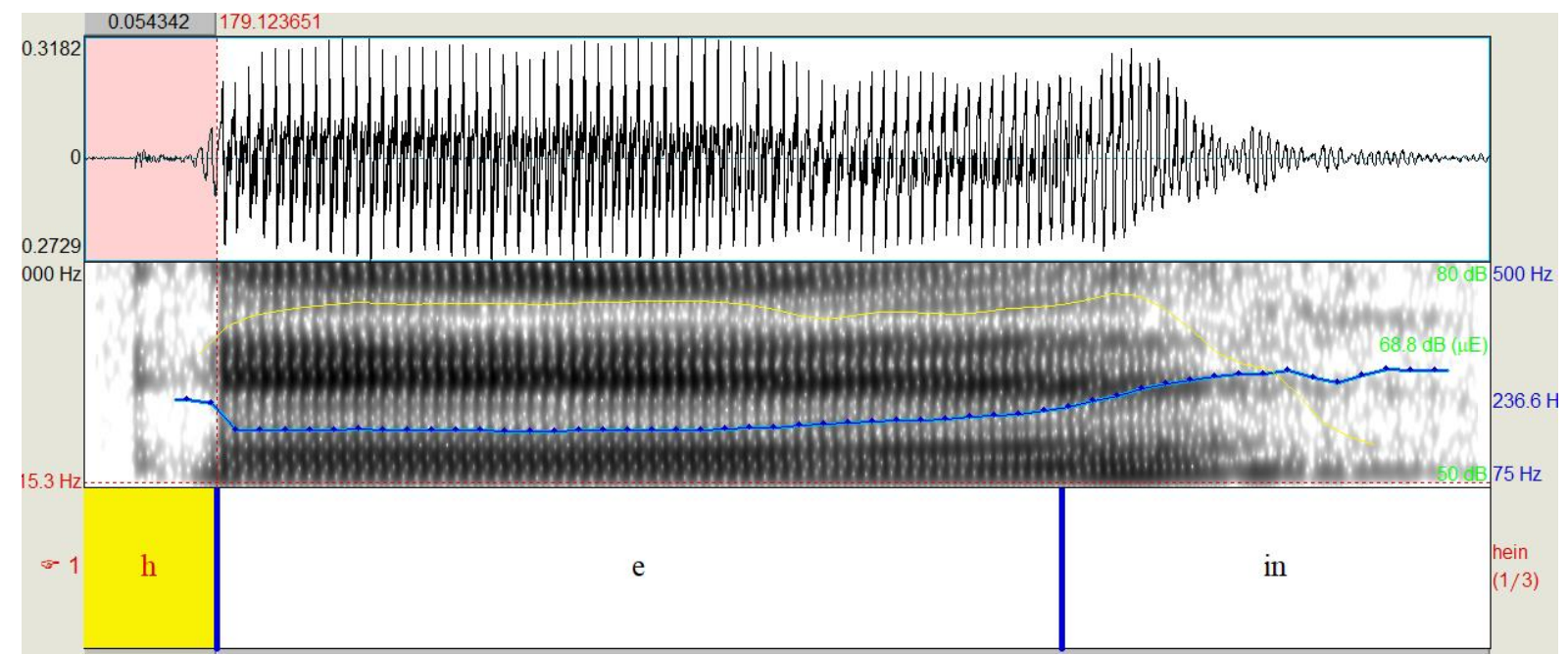

This is the spectrum for /heĩ/. There is a clear glottal presence at the beginning of this word. This assumption is based on the length of the temporal irregularity of pulses at the onset of the vowel. The time duration is $37 \mathrm{~ms}$. Compare this to /ha/ below. /ha/ has a shorter $/ \mathrm{h} /$ length before the vowel. The time duration is $22 \mathrm{~ms}$. The difference between the time duration is $14 \mathrm{~ms}$. 


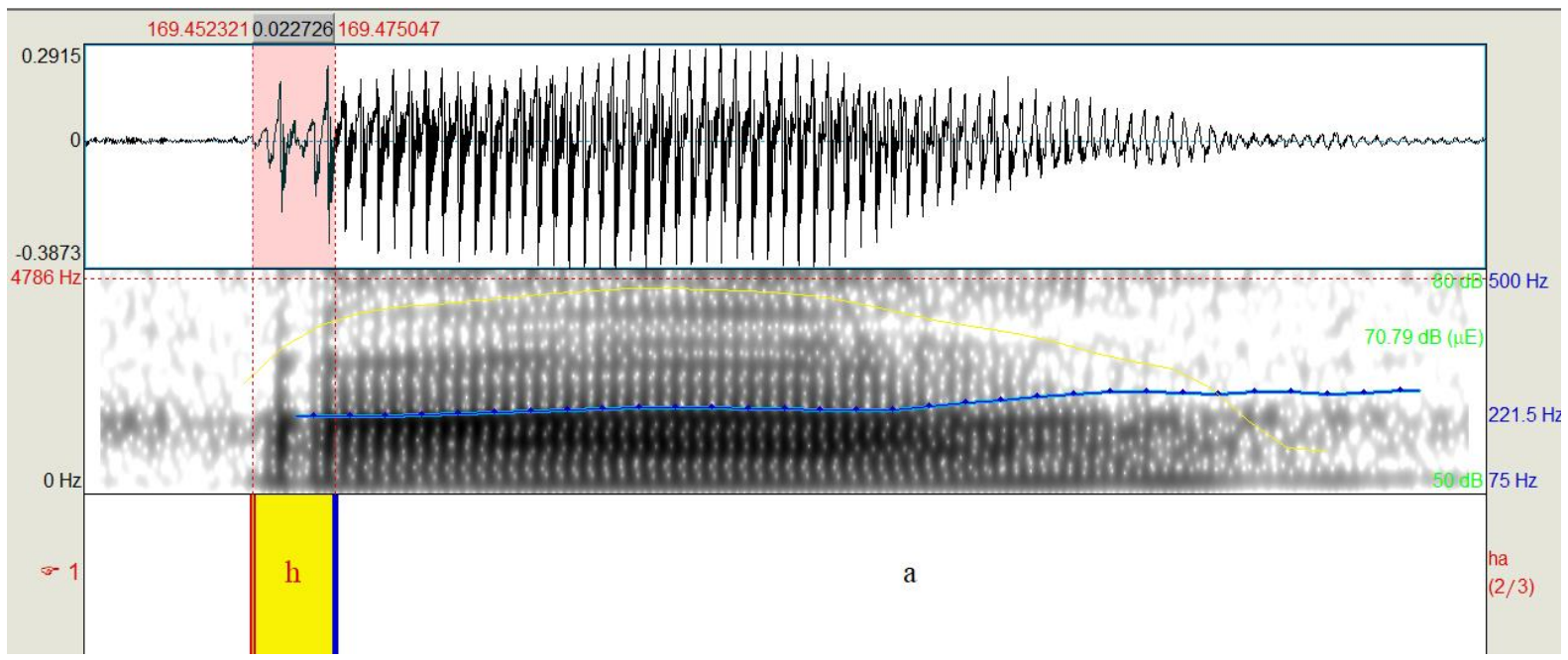

Based on the above observation, it became eminent to observe the vowels following the glottal sound at the word-initial position. This was necessary because it wasn't clear why the glottal sound will be clearer when it is close to front vowels than when it is close to back vowels. The assumption is that these vowels influence the quality of the glottal sound. If this is the case, then there is a need to investigate how these vowels are pronounced without the glottal sound preceding them in comparison to those preceded by the glottal sound. The words with no initial glottal sound representation were investigated first. They include:

\section{Eyin /عjĩ/- egg,}

Ada /ada/ - cutlass,

Igi /igi/- tree,

iwe- book etc. (see appendix four for the full list).

The interesting outcome is that these vowels at the word-initial position have the same phonological realization as the vowels preceded by the glottal sound. To illustrate this, the vowel /a/ in 'ha' which means 'to scratch' and the initial vowel in 'ada' which means 'cutlass' have a similar glottal realization at the word-initial position. Compare figure 3.3 and 3.4 below. 
Fig. 3.3 /ha/

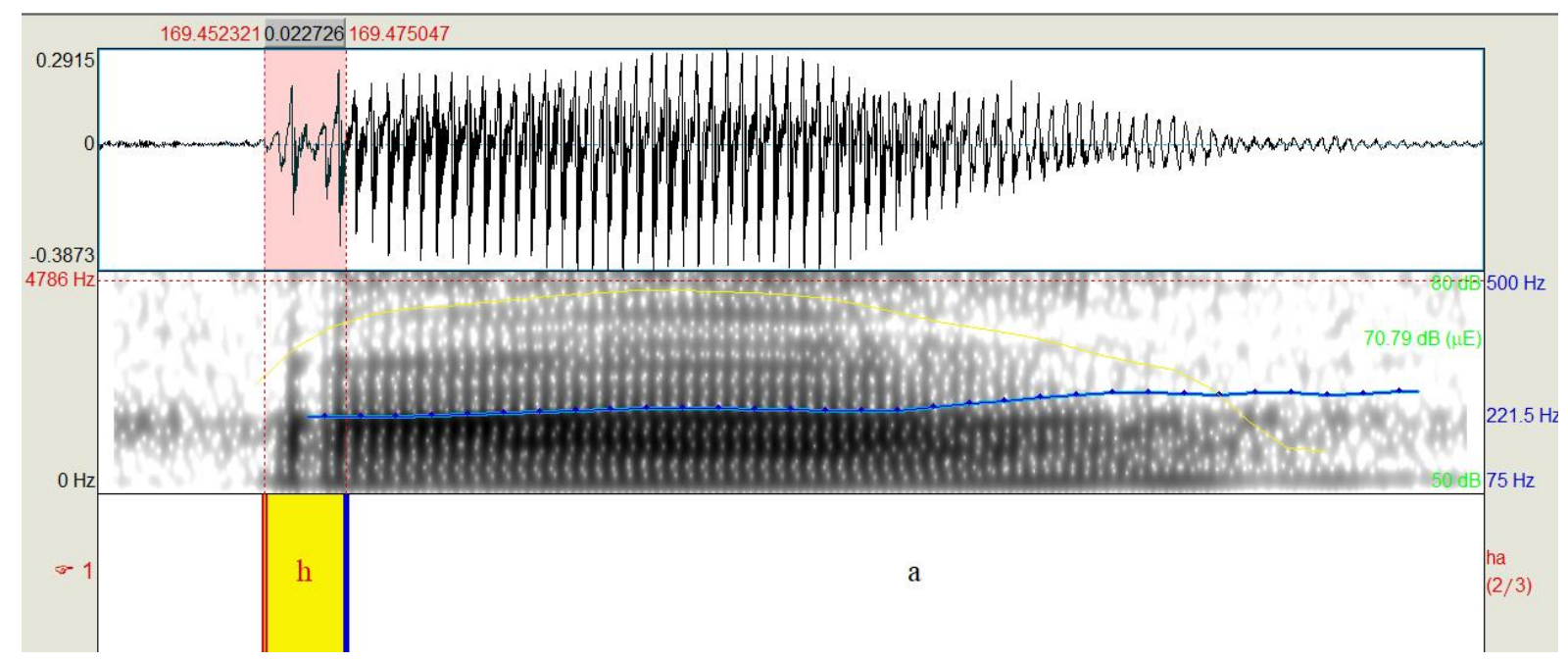

Fig. 3.4 /ada/

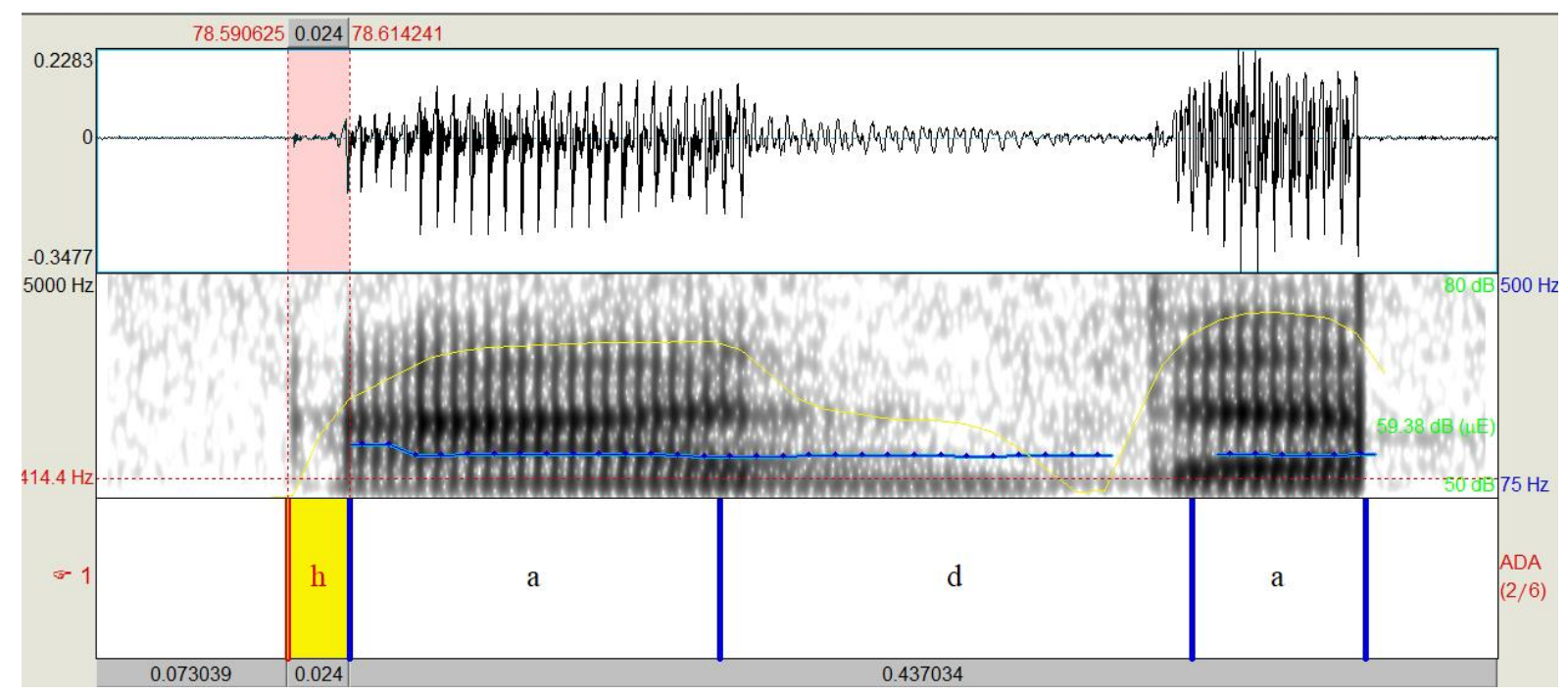

Based on the above observation, it may imply that the vowel following the glottal sound does not only influence the quality of the /h/ sound, but it may be the base for the glottal sound variations i.e. the realization of a fricative or a stop. This influence is not new as Akinlabi (1991) indicated that glottal glide is influenced by the homo-organic vowel adjacent to it, thereby making it voiced when it is originally voiceless. This is not peculiar to $/ \mathrm{h} /$ alone but also to $/ \mathrm{w} /$ and $/ \mathrm{j} /$, where the homorganic nasal vowels give rise to the neutralization of the oral glides /w/ and /j/ preceding them yielding to a voiced placeless glide $/ \mathrm{h} /$. 
Based on the above observation that the vowel-initial words and the $/ \mathrm{h} /$-initial words in Yoruba are pronounced the same way, I hypothesize that the meaning of the words with $/ \mathrm{h} / \mathrm{as}$ onset and vowel as onset would be similar; since the vowel-initial words and words starting with $/ \mathrm{h} /$ are pronounced the same way. Thus, this implies that the presence or absence of the glottal sound at the word-initial position is not contrastive; therefore making /a/ and /ha/ have the same meaning if the tone is similar. This hypothesis was found to be correct after my investigation. To further buttress this point, the table below shows the glottal sound before all the primary vowels in Yoruba (except/i/ as there is no sequence of /hi/ in Yoruba) compared with similar words with no glottal sound at the beginning.

Table 3.1 Glottal initial words versus vowel initial words

\begin{tabular}{|c|c|c|c|}
\hline Initial /h/ words & Meaning & Vowel initial words & Meaning \\
\hline /ho/ and [o] & Shout & /orĩ/ and [horĩ] & Song \\
\hline$/$ hũ/ and $[\tilde{u}]$ & Weave & /aja/ and [haja] & Dog \\
\hline /hã/ and [ã] & Show & /عrĩ/ and [herĩ] & Laughter \\
\hline /ha/ and [a] & Scratch & /ikã/ and [hikã] & Termite \\
\hline$/$ he/ and $[\mathrm{e}]$ & Find & /ədũ/ and [hodũ] & Year \\
\hline 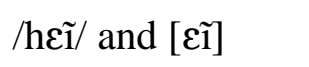 & Yes & / $\varepsilon j \varepsilon /$ and [heje] & Blood \\
\hline
\end{tabular}

This table shows that the insertion and deletion of $/ \mathrm{h} /$ at the word-initial position is not contrastive.

Although in Yoruba the words on the left have the glottal sound at the word-initial position, phonologically the $/ \mathrm{h} /$ sound presence or absence is not contrastive in this position.

I mentioned earlier that the glottal sound was sometimes realized as a glottal stop / / and at other times as glottal fricative $/ \mathrm{h} /$. however, when or where this variation occurs is not clear. This means that the position of occurrence of the glottal fricative or glottal stop is not 
predictable. Therefore, an investigation into the position of occurrence of these glottal realizations will be my next focus.

I clarified earlier that the presence and absence of the glottal sound at the word-initial position in Yoruba do not produce semantic distinctions. Secondly, the vowel-initial words and glottal-initial words are pronounced the same, such that all the word-initial vowel have glottal realizations at the onset. Thirdly, the meaning of the words with initial glottal sounds and the words with vowels as initial sounds have the same meaning. Based on these assumptions, sixtyone words were investigated. These are words in Yoruba with the vowel as initial phoneme and the glottal sound as the initial and medial phoneme. The vowel initial-words are part of the sixty-two words because the focus of the present analysis is solely on the glottal realizations at the onset of these vowels. These sixty-two words were pronounced by the Yoruba participants.

The recordings were investigated using the Praat spectrum (Boersma \& Weenink 2018). After the investigation, these words (with the vowel as initial phoneme and the glottal sound as an initial phoneme), showed that the glottal stop is realized before all vowel and the glottal fricative is also realized before all vowels except / $/ \mathrm{J}$ and / $\mathrm{u} /$ sound. Please note that the number of the data investigated for $/ \mathrm{J} /$ and $/ \mathrm{u} /$ may not be enough for such a conclusion as there were only five words with / $/$ / vowel in my data and one word with /u/ vowel. (see appendix one for the full analysis). Therefore, it still unclear where the glottal fricative or glottal stop is used since they both occur before all vowels at the word-initial position. The table below gives a numeric summary of this analysis. 
Table 3.2.0 Glottal Frequency of glottal-initial words and vowel-initial words

\begin{tabular}{|c|c|c|c|c|}
\hline $\begin{array}{l}\text { Word-initial glottal } \\
\text { sounds }\end{array}$ & $\begin{array}{l}\text { Total number of } \\
\text { words }\end{array}$ & $\begin{array}{l}\text { Glottal } \\
\text { Fricatives }\end{array}$ & Glottal Stop & Neutral \\
\hline Before /i/ & 19 & 3 & 15 & 1 \\
\hline Before / $\varepsilon /$ & 8 & 2 & 6 & 0 \\
\hline Before /e/ & 7 & 1 & 6 & 0 \\
\hline Before /o/ & 4 & 1 & 3 & 0 \\
\hline Before /כ/ & 5 & 0 & 5 & 0 \\
\hline Before /u/ & 1 & 0 & 1 & 0 \\
\hline Before /a/ & 17 & 7 & 10 & 0 \\
\hline Total & 61 & 14 & 46 & 1 \\
\hline
\end{tabular}

These table shows underlyingly glottal-initial words /h/ and supposed underlyingly non-glottal initial words i.e. vowel-initial words.

These figures came from the pronunciations of the three Yoruba participants. It is worthy to note that their pronunciations are slightly different because of the surrounding noise and the differences in individual voices. For example, the male participant voice was more 'intense' than that of the female participants.

The difference between the glottal fricatives and glottal stop is that fricatives show up as a continuous black noise with a fricative noise. On the other hand, the glottal stop has irregular spaced vertical lines in the spectrum which sounded like an abrupt 'tap-like' sound. The table below gives a summary of the above table in percentages. 
Table 3.2.1 Glottal Percentage Frequency based on table 3.2.0

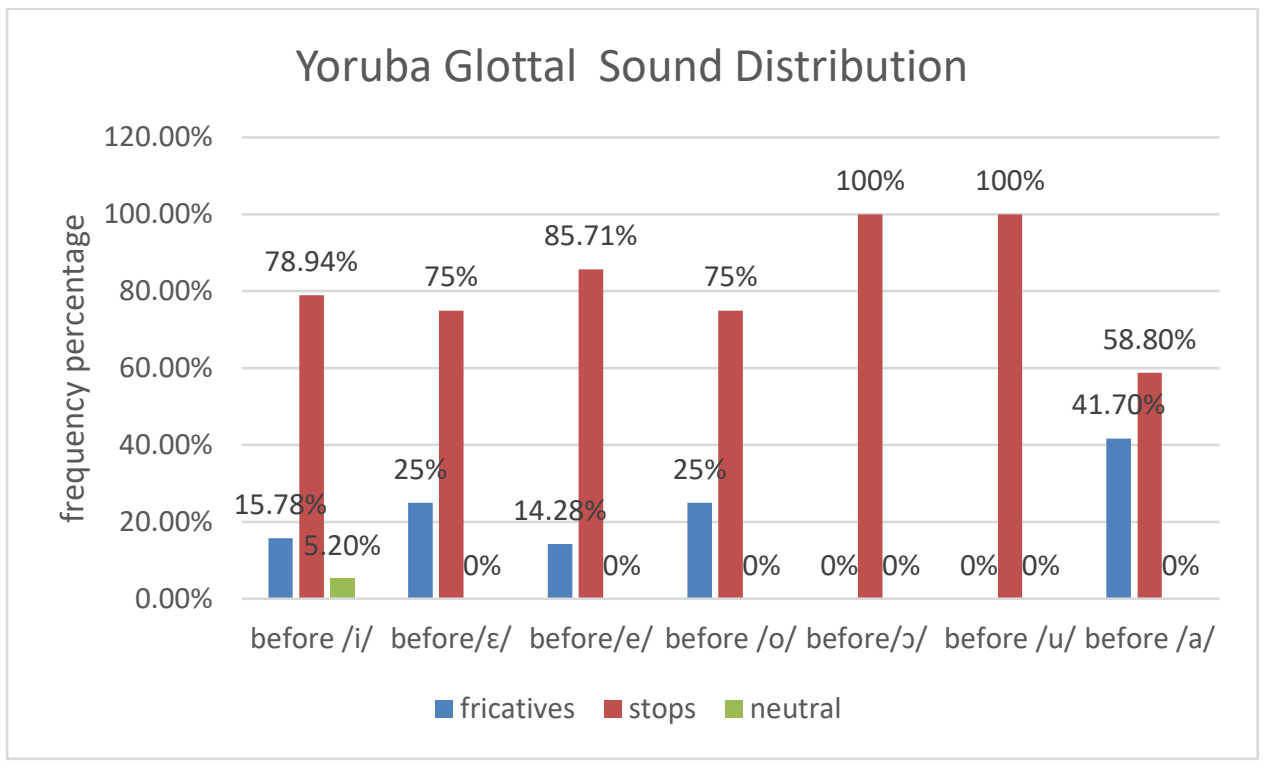

That said, the above analysis partially supports the claim by Oyebade (1992) where she recognized the glottal sound in the Yoruba sound inventory as a glottal fricative.

Since the glottal fricative and glottal stop occur before all the vowels in Yoruba, it means that there should be an extra factor(s) that differentiates or indicates when the glottal fricative or glottal stop is used. Since Yoruba is a tonal language, I checked if the tone affects the glottal sound dimension to be either a fricative or a stop. I realized that the tone doesn't affect or cause this dimension. An example is /عyĩ/ (egg) and /Eri/ (testimony), both have the

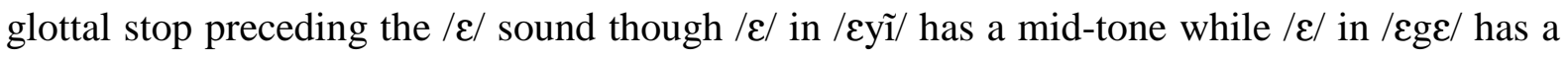
low tone. This shows that tone doesn't influence the quality, presence or absence of the glottal sound at the word-initial position.

The above table (3.2.0) showed that the frequency of the glottal stop at the word-initial position is higher than that of the glottal fricative. In fact, it is not out of place to assume that /h/ is underlyingly a glottal stop in this position. Looking at the words that started with the glottal sound in the Yoruba (here vowel-initial words are not included in this category; only 
the glottal-initial words), it is glaring that they all have the glottal stop at the onset. The table below shows the glottal sound at the word-initial position. This glottal sound is tested before all the primary vowels in Yoruba (except the /i/ vowel i.e. /hi/ sequence), because Yoruba do not permit consonant clusters. This is better illustrated with the table below.

Table 3.3 Underlying glottal sound $/ \mathrm{h} /$ at the word-initial position (glottal stop).

\begin{tabular}{|l|l|l|l|}
\hline 1 & $/ \mathrm{O} /$ & $\begin{array}{l}\text { /ho/ Ho-boiling } \\
\text { (water) }\end{array}$ & glottal stop \\
\hline 2 & $/ \mathrm{J} /$ & /ho/ Ho- run & glottal stop \\
\hline 3 & $/ \mathrm{a} /$ & $/ \mathrm{ha} / \mathrm{Ha}-$ scratch & glottal stop \\
\hline 4 & $/ \mathrm{e} /$ & /he/ He- find & glottal stop \\
\hline 5 & $/ \varepsilon /$ & /heĩ/ Hein - yes & glottal stop \\
\hline 6 & $/ \mathrm{u} /$ & $/$ hũ/ Hun -weave & glottal stop \\
\hline
\end{tabular}

Please note that these words are written with letter ' $h$ ' at the onset in Yoruba orthography.

The only reasonable assumption here is that, the words that were written with ' $h$ ' in Yoruba orthography has a vivid glottal presence at the onset while the other words that were not written in the orthography with an ' $h$ ' at the onset were not vividly pronounced or the glottal sound was in the process of being lost as at the time the Yoruba language was coded (i.e. Written); thus, leaving a trace that has been reduced to just breathiness. Therefore, the words with a breathy voice at the onset were not written with glottal representation in the Yoruba orthography. To ascertain if the above assumption is right, words from other dialects of Yoruba need to be investigated. I don't have such words in my data, as a result, I can't make a valid conclusion. Despite this hitch in my analysis, it will not be out of place to assume that the glottal sound in Yoruba is at the verge of being lost based on the pattern observed so far. 
Another way to look at it is that Yoruba does not have the glottal sound at the wordinitial position but as the language evolved it was introduced into the sound system. This assumption may not be totally tenable because according to Akinlabi (1991), the glottal approximant is the base for synchronic alternation for other glides (w, and $\mathrm{j}$ ) at the word-initial position. If that be the case, then / $\mathrm{h} /$ may not have been introduced into the sound system.

Since a clear conclusion cannot be made from the analysis so far based on glottal sound at the word-initial position, the glottal sound at the word medial position will be investigated in hope that this will give a clearer picture of the way to effectively describe the Yoruba glottal sound. Therefore, the next step is to check the medial $/ \mathrm{h} /$ and see how it is realized. Twentyone words were observed. These are some of the words.

Table 3.4 Word-medial glottal sound (Glottal Glide)

\begin{tabular}{|l|l|}
\hline Words & The medial glottal sound manner of articulation \\
\hline Iho /iho/ & glottal glide \\
\hline Ohun /ohũ/ & glottal glide \\
\hline Ehoro /ehoro/ & glottal glide \\
\hline Ahere /ahere/ & glottal glide \\
\hline Ihoho /ihoho/ & glottal glide \\
\hline ehin / chĩ/ & glottal glide \\
\hline
\end{tabular}

(see appendix two for full list)

Table 3.4 above clearly shows that the medial $/ \mathrm{h} /$ is always pronounced as a glottal glide. A vivid example of how the glide appears on pratts can be seen in figure 3.5 /ihoho/. 
Fig. 3.5 /ihoho/

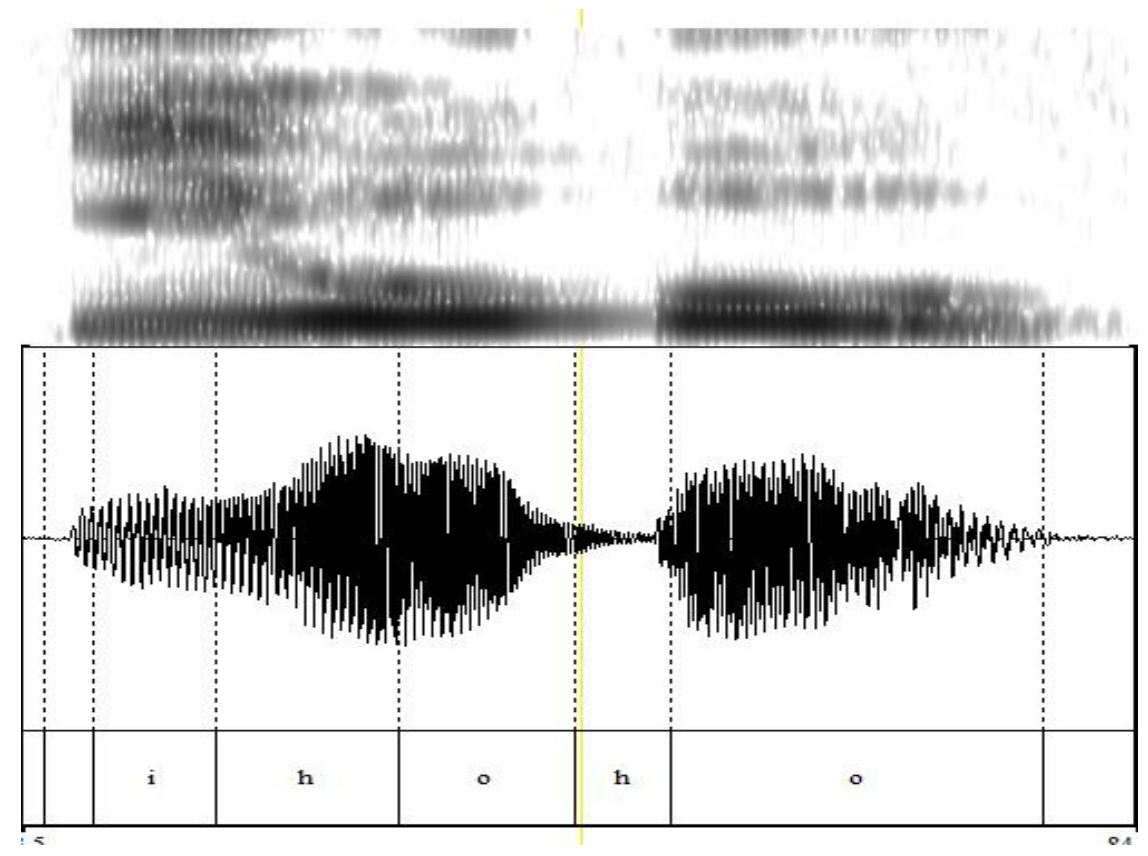

The spectrum in fig, 3.5 /ihoho/ shows the first glottal sound gliding between the front /i/ and /o/ back vowels, which indicate that it is a glottal glide or zero. The second one looks clearly like a glottal stop. This is obvious because the amplitude of the waveform decreases to almost silence, then the spectrograph goes almost entirely white, and then there is a small vertical line at the onset of the following vowel, indicating some type of plosive mechanism.

The first part of the spectrum showing the /h/ gliding between two vowels totally supports Akinlabi's analysis. To re-iterate Akinlabi's point, there are three distinctive glides in Yoruba sound system /w, j, h/. The examples he gave were: 'iwa'/iwa/, 'iha'/iha/ and 'iya'/ija/. Homoorganic nasal vowels spread their place feature to the preceding oral glides $/ \mathrm{w} /$ and $/ \mathrm{j} / \mathrm{at}$ the word-medial position, therefore leaving the oral glides with their laryngeal feature. Thus, the result is a glottal glide [h]. E.g.

11. Owun /owũ/ - ohun [ohũ] and

Iyin /ijĩ/ - ihin. [ihĩ] 
He explained here that there is a place deletion (i.e. assimilation of the oral glides by the homoorganic nasal vowels) which results in a placeless glide [h].

However, if the following vowel is not a homo-organic nasal vowel, this alternation is blocked. For example;

12. owu /owu/- *ohu [ohu] and iyi /iyi/ - *ihi [ihi]

This alternation wouldn't work because it is not a nasalized homo-organic vowel i.e. nasalized /i/ and /u/ that follow the oral glide. Also, the synchronization into the glottal glide by the oral glides is limited to the word-medial position. This implies that $/ \mathrm{w} /$ and $/ \mathrm{j} /$ are the root nodes that are assimilated by the homo-organic nasal vowels and thus the base for the synchronization of $[\mathrm{h}]$. As I indicated in chapter two, this $[\mathrm{h}]$ is different from $/ \mathrm{h} / .[\mathrm{h}]$ is a derivation from oral glides /w/ and /j/ while /h/ is a distinct phoneme just like /w/ and /j/

At the word-initial position, however, the glottal glide $/ \mathrm{h} /$ is the root node as it is the base for synchronization. For example:

13. hu /hu/- changes to wu [wu] (to grow).

But you cannot have

\section{Wundia /wũdia/- *hundia [hũdia]}

This alternation is blocked because $/ \mathrm{h} /$ is the root node that determines the alternation in this position and not [w]. (see Akinlabi 1991:23 for details). Please note that there is no sequence of /hi/ at the word-initial position in Yoruba. Therefore, alternation between [j] and $/ \mathrm{h} / \mathrm{cannot}$ be tested at the word-initial position. 
What is clear in my analysis so far and relevant to this research is that; the presence or absence of the glottal sound at the word-initial position is not contrastive. Also, according to Akinlabi (1991), the glottal glide [h] (which derived from $/ \mathrm{w} /$ and $/ \mathrm{j} /$ ) is not contrastive at the word-medial position after an alternation with $/ \mathrm{w} /$ or $/ \mathrm{j} /$. For example:

15. /owũ/ - [ohũ]- [oũ] - 'tortoise'

/olaniwũ/- [olanihũ]- [эlaniũ] - 'a name'

$/ \varepsilon j \tilde{1} /-[\varepsilon h i ̃] ~-~[\varepsilon \tilde{i}]-$ 'back'

/ayĩla/- [ahĩla]- [aĩla] - 'a name’' (see Akinlabi, 1991, pg. 21 for more examples).

Also, the presence or absence of the glottal $/ \mathrm{h} /$ at the word-medial position is not also contrastive. See illustration in example 16 below.

$$
\begin{aligned}
& \text { 16. /ahere/- [aere] } \\
& \text { /aheso/ - [aeso] } \\
& \text { /iho/- [io] } \\
& \text { /Ehonu/- [Eonu] } \\
& \text { /ehoro/ - [eoro] }
\end{aligned}
$$

Therefore, it can be concluded that there are several realizations of the glottal sound $/ \mathrm{h} / \mathrm{in}$ Yoruba: it could be a glottal glide, zero or a glottal stop at the word-medial position, and either a weakened glottal fricative, a zero or a glottal stop at the word-initial position. From the foregoing, /h/ freely varies between a (weak/lenis) fricative, a zero, a glottal glide, and a glottal stop.

Finally, the contrast between $/ \mathrm{h} /$ and zero at the word-initial position is weakened or absent for my speakers (who speak the standard Yoruba variety). Another way to look at this is that $/ \mathrm{h} /$ is variably deleting at the word-initial position, and when it deletes the form is 
pronounced just like a vowel-initial one, with some amount of variation between glottal articulations.

In conclusion, what this means for the Yoruba language is that the phonological possibility of $/ \mathrm{h} /$ as an initial consonant is either in the process of being lost or is already gone from my speakers' variety which is the standard Yoruba variety. 


\section{CHAPTER 4}

\section{/h/ DROPPING AND INSERTION INTO ENGLISH WORDS}

In the previous chapter, I tried to decipher the nature and uniqueness of the Yoruba $/ \mathrm{h} /$. In this chapter, I will focus on the reason for $/ \mathrm{h} / \mathrm{dropping}$ and $/ \mathrm{h} / \mathrm{insertion}$ at the word-initial position by the Yoruba speakers into their English pronunciation.

It can be predicted that the Yoruba-English speakers transfer the uniqueness and pattern of the Yoruba glottal realizations into English language words. This hypothesis, if found true, should answer the question of $/ \mathrm{h} /$ insertion and dropping by the Yoruba-English speakers.

It is important at this point to give a short summary of previous research on the English glottal sound. Pierrehumbert and Talkin (1992), who researched the effect of prosodic structure on how segments are pronounced, claimed that the production of laryngeal consonants depends strongly on both word and phrase level prosody. They did in-depth quantitative research on the English glottal fricative /h/ and the glottal stop [?]. They found out that the position of $/ \mathrm{h} /$ in the word and the phrasal stress affect how it is pronounced. They further explained that although stressed syllables had a high percentage of noticeable glottalization [?] which appeared in all positions (initial, medial and final positions) the reduced or unstressed syllables had a low percentage of [?] except at a phrase boundary (see pgs. 114- 115); this indicates that the phrase boundary plays a vital role in the realization of the glottal sound. They also claim that speakers insert glottal stops at the beginnings of vowel-initial words in phrase-initial position; and that, this glottal stop is in phonemic contrast with the presence of a glottal fricative.

Based on the insights given in the above research, I will compare the phonological realization of the English /h/ to that of the Yoruba /h/ to ascertain the differences. Then I will 
use the result to decipher the reasons for the perceived $/ \mathrm{h} /$ dropping and insertion by the Yoruba-English speakers.

According to my findings in chapter three, the Yoruba glottal sound has three types of realizations at the word-initial position. It is realized as a glottal stop, and at other times, as a lenis or weakened glottal fricative or a zero realization. I also noted that there is a free variation between these realizations. The assumption is that if the Yoruba speaker uses a zero at the word-initial position where there is originally a glottal fricative in English, it will be perceived as $/ \mathrm{h} /$ dropping. On the other hand, if they pronounce a fricative before a vowel, even if it is a weak fricative, it will be perceived as insertion because the native speaker is expecting glottalization [?] and not frication.

To investigate the above assumption, the first step is to check if the Yoruba-English speakers pronounce the English /h/ at the word-initial position the same way they pronounce the Yoruba /h/ in this position. Examples of the words investigated include; head, horn, and house (see appendix three for the full list). After observing the Yoruba speaker's pronunciation, I realized that they pronounce these words the same way they pronounce words with a similar sequence in Yoruba. Some of the examples are health and hein (yes), and horn and ho (scratch). See the spectrum below for clarification. 
Fig. 4.1 /hعĩ/

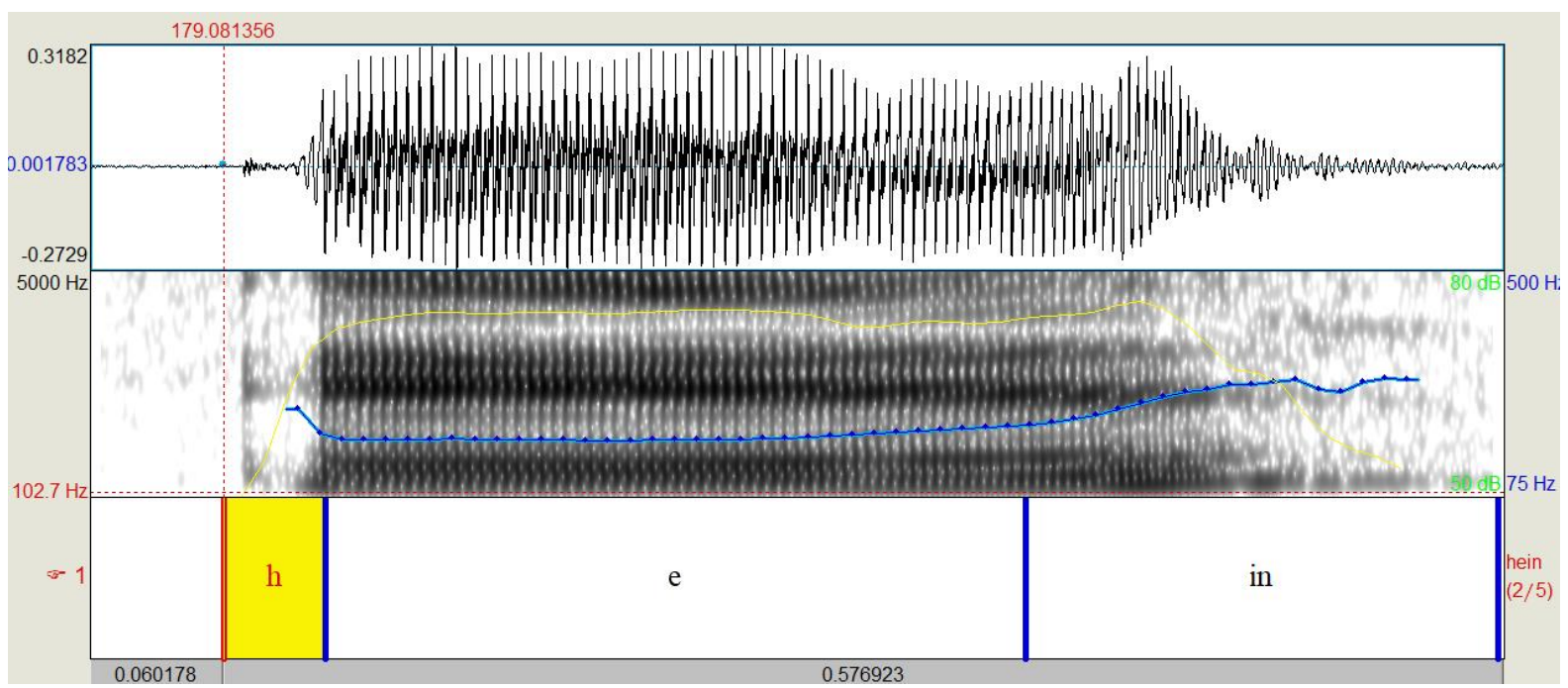

Fig. 4.2. Health pronounced as /het/ by the participant.

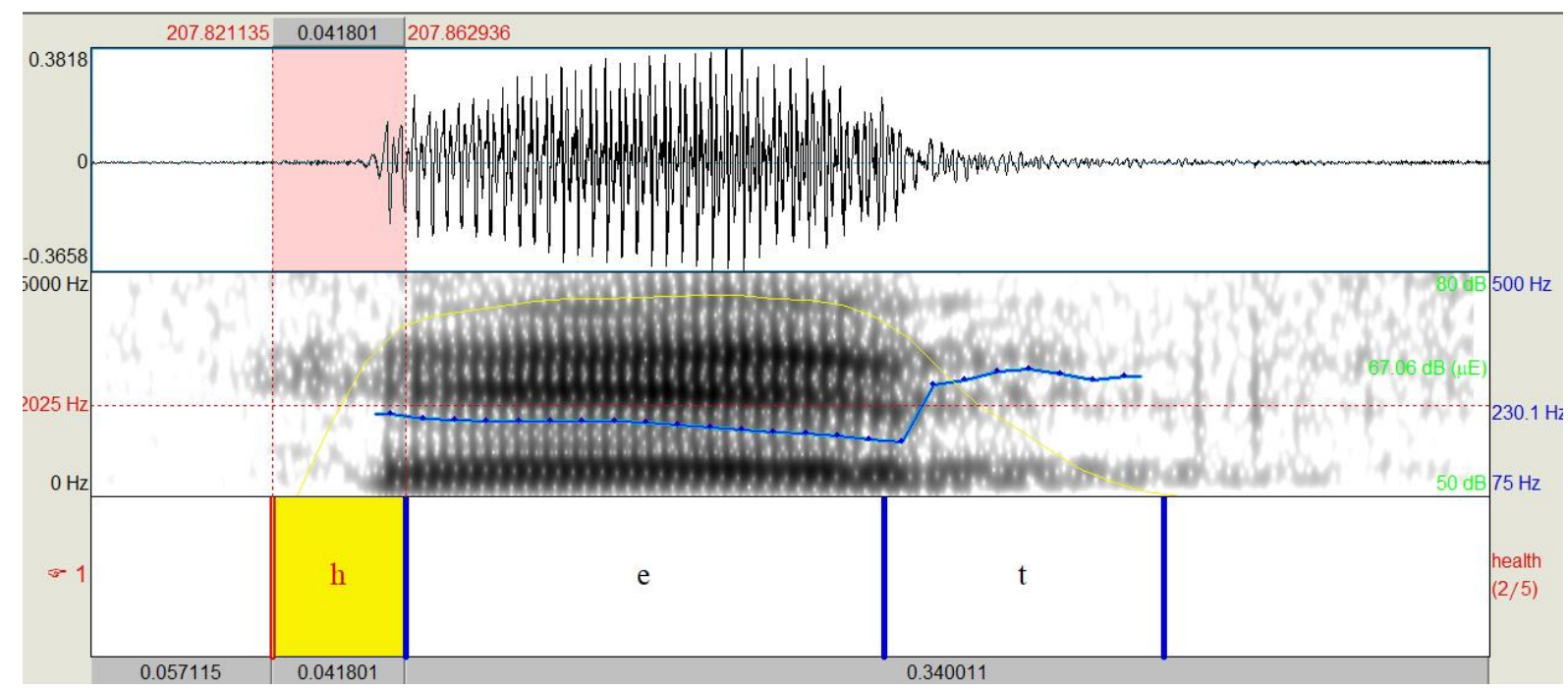

There is a similarity in the pronunciation of these words in Yoruba and English. The $/ \mathrm{h} / \mathrm{at}$ the beginning of both words has shades of black noise which is continuous until the onset of the vowel after it. The duration of both /h/ is almost the same. /heĩ/ has a duration of $37 \mathrm{~ms}$ and /het/ has a duration of $41 \mathrm{~ms}$. This resemblance in pronunciation can be seen in /horn / and /ho/ below. 
Fig.4.3. /horn/

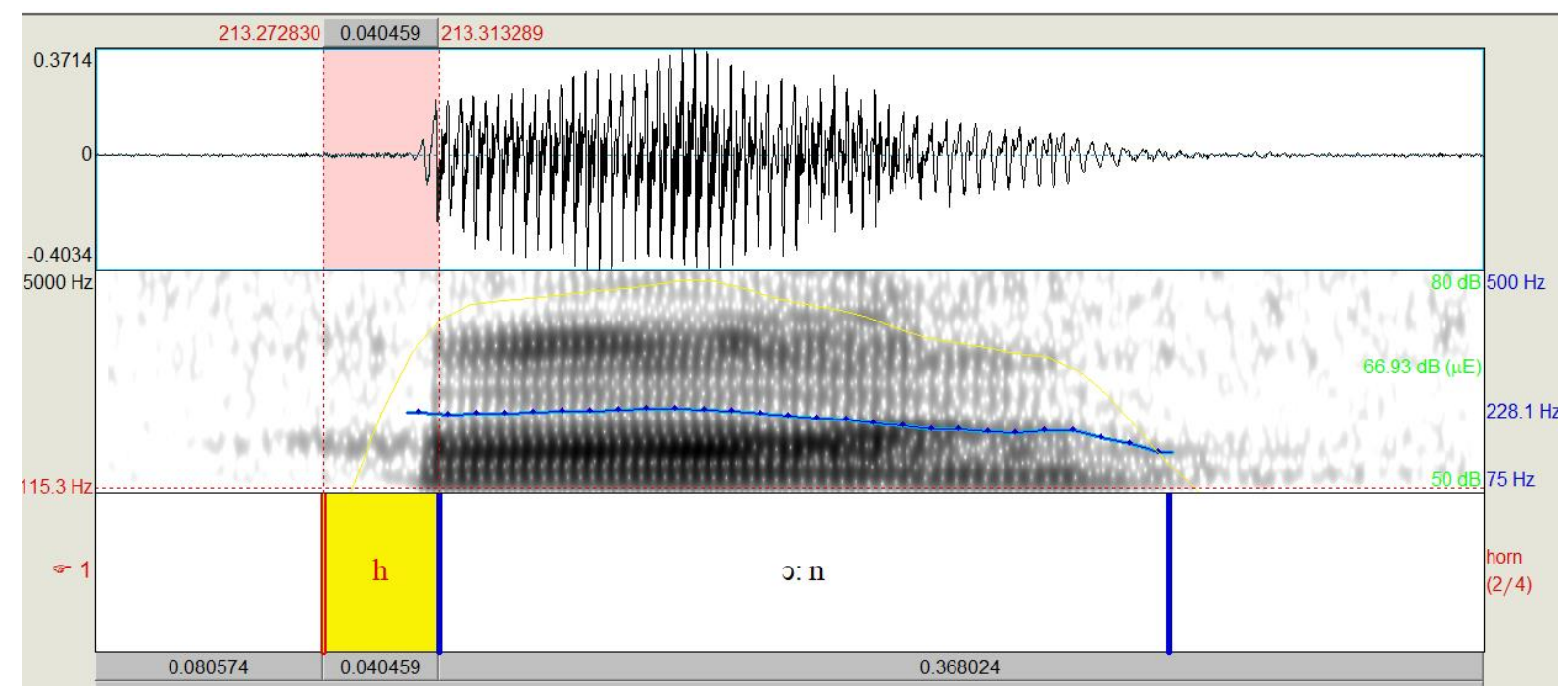

Fig. 4.4. /ho/

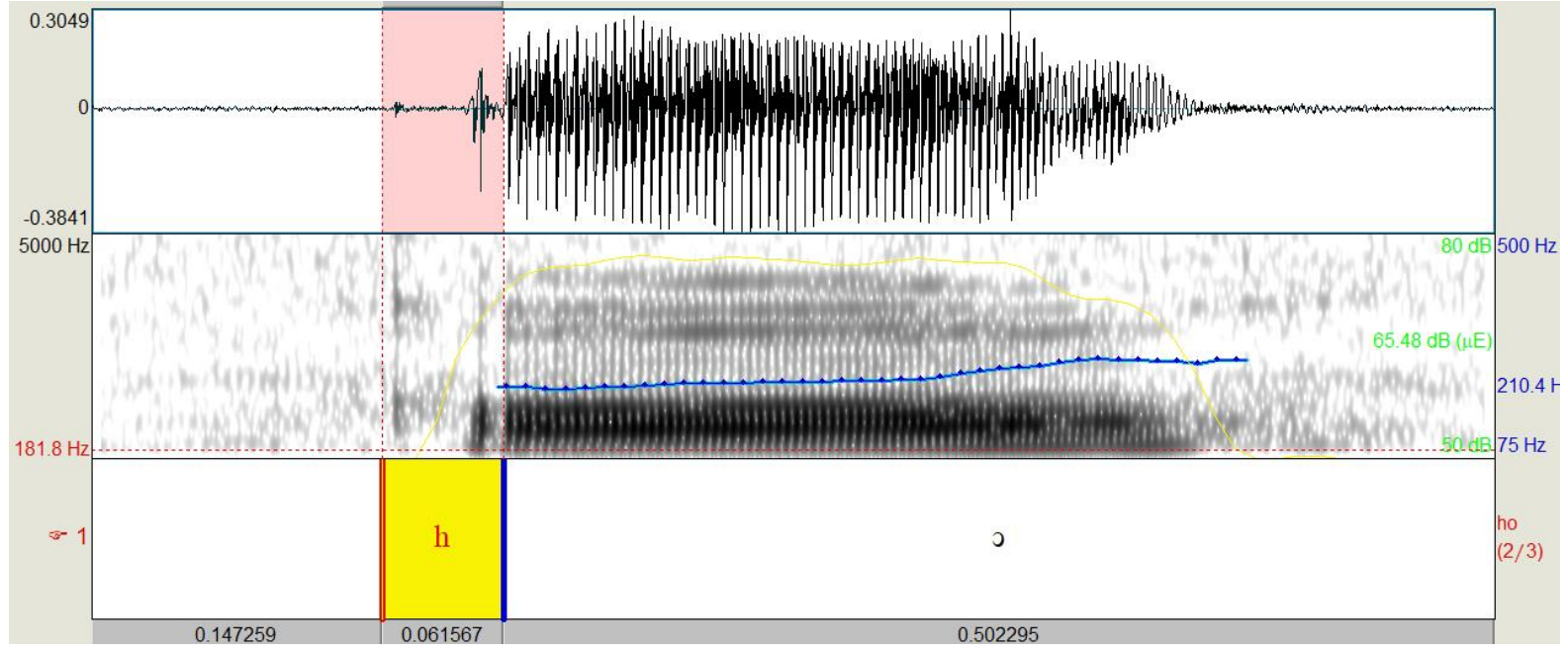

The above examples show a resemblance of initial $/ \mathrm{h} /$ pronunciation especially in the length of the initial /h/ in English and Yoruba by the Yoruba speaking participants. The length for /ho/ is $61 \mathrm{~ms}$ and the length for /horn/ is $40 \mathrm{~ms}$. This confirms the hypothesis that the YorubaEnglish speakers transfer the attributes of the Yoruba /h/ into English words. 
The next step is to check how the Yoruba /h/ pronunciation differs from English $/ \mathrm{h} /$ pronunciation as it is pertinent to compare the pronunciations. This will be done by comparing the words pronounced by the American native speaker and the Yoruba-English speakers. Examples of English words examined include: head, hear, etc (see appendix for full list).

Fig. 4.5. /hed/- Yoruba (1) participant pronunciation

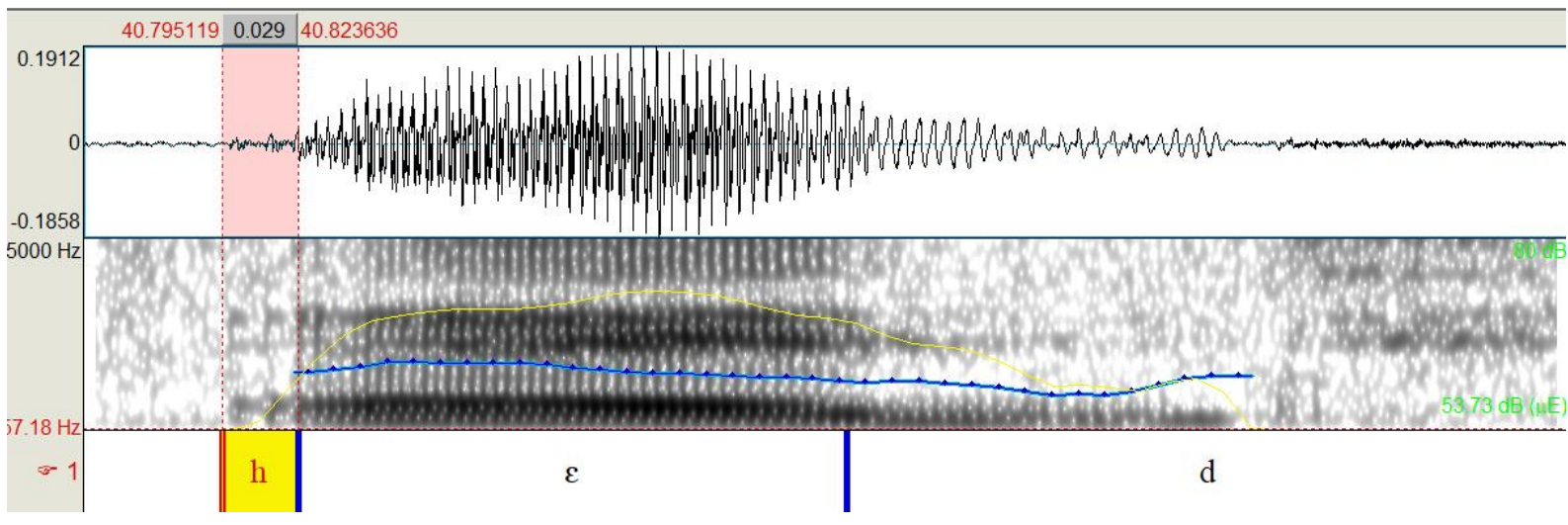

Fig. 4.6. /hed/- American native speaker's pronunciation

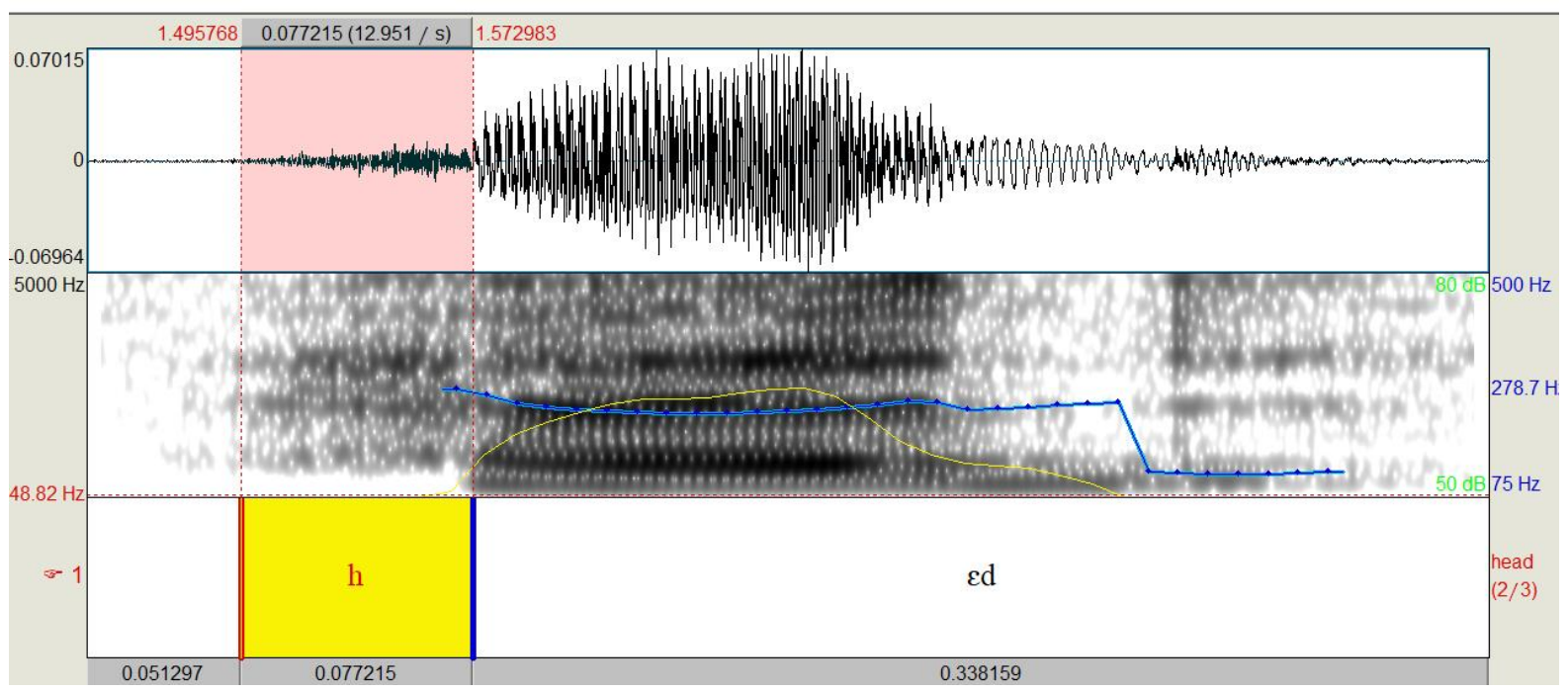

The spectrum above shows a clear difference between the native speaker's and the Yoruba participants pronunciation. The native speaker has a clear longer $/ \mathrm{h} / \mathrm{before}$ the vowel with a duration of $77 \mathrm{~ms}$ while the first Yoruba participant had a reduced $/ \mathrm{h} /$ with a duration of $29 \mathrm{~ms}$. Furthermore, the native speaker pronounced a fricative while the Yoruba speaker pronounced 
glottalization/stop, with some amount of glottal frication (breathiness) at the beginning. This is clearer in figure 4.7. Although the second Yoruba participant had a longer $/ \mathrm{h} /$ duration (89 $\mathrm{ms})$, compared to that of the native speaker $(77 \mathrm{~ms})$, the spectrum clearly shows that there is more frication in the native speaker's $/ \mathrm{h} /$ compared to the Yoruba speaker's $/ \mathrm{h} /$. Compare figure 4.7 and 4.8

Fig. 4.7. /hed/- Yoruba (2) participant pronunciation.

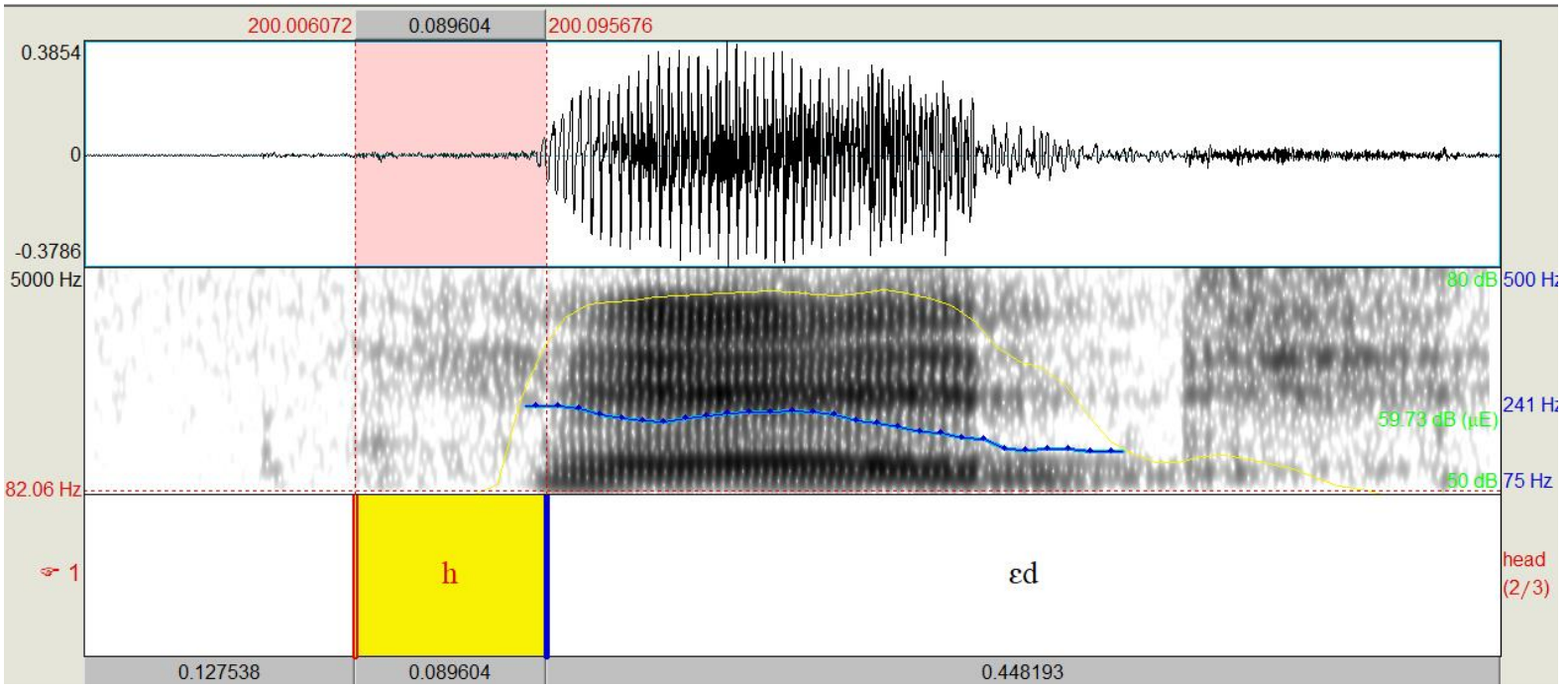

Fig. 4.8. /hed/- American native speaker's pronunciation

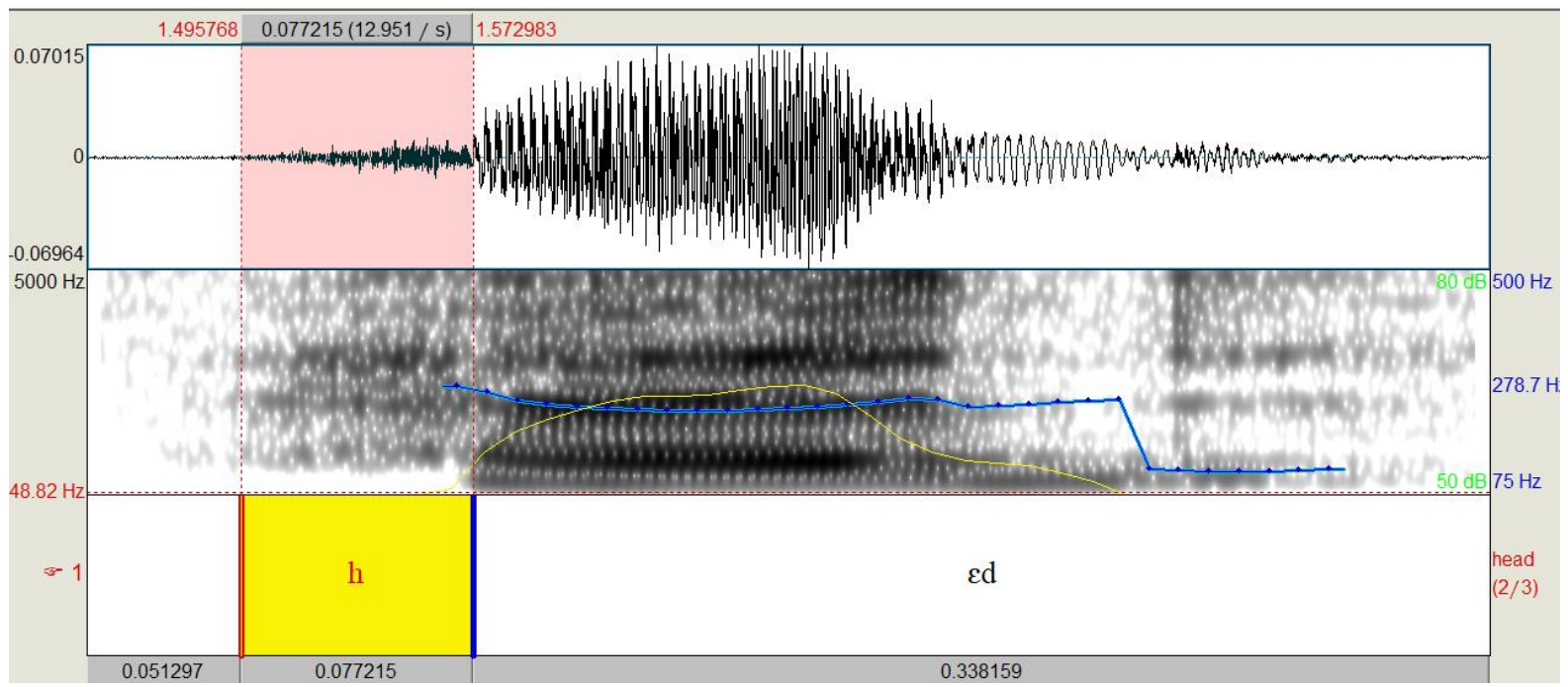


This clearly shows the transfer of the Yoruba /h/ attributes into the pronunciation of English. Since the Yoruba speakers alternate the glottal stop, glottal fricative or breathiness and zero realization in this position, it indicates that the pronunciations will be perceived by the native speaker differently, such that a zero or breathiness will be perceived as deletion, while glottal frication or breathiness may be perceived as insertion, if it is pronounced before a vowel-initial word in English. This is because the native speaker would pronounce a glottal stop before a vowel-initial word.

To further buttress this point, one of the observations in chapter three was that there is no sequence of $* / \mathrm{hi} /$ in Yoruba, but there is a sequence of $/ \mathrm{hi} /$ in English. It will not be out of place to check what the Yoruba speaker pronounces when they pronounce words starting with this sequence. An example hear-/hir/ in English.

Fig. 4.9. /hir/ by the Yoruba-English speaker

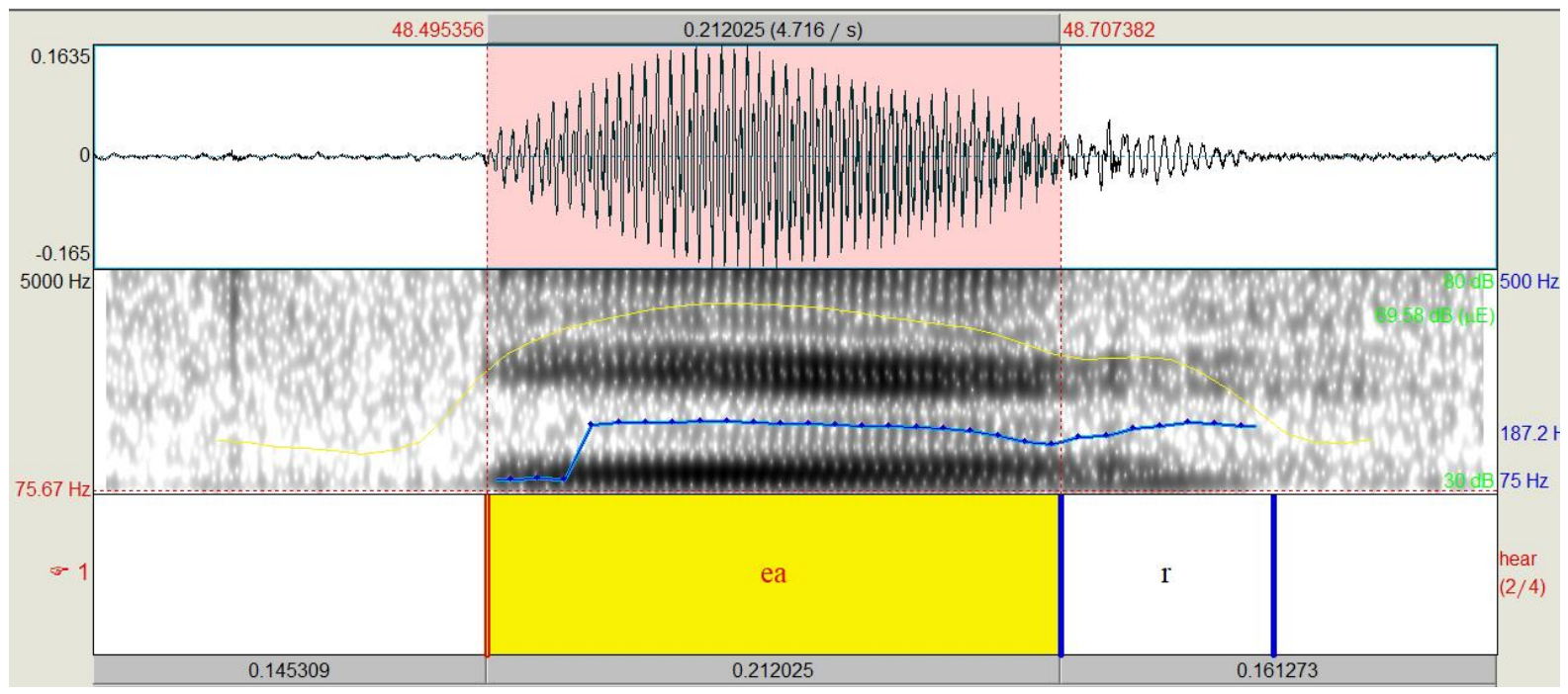

Here the Yoruba native speaker drops /h/ in this position. All of my participants did the same thing. I compared this pronunciation with the American native speaker's pronunciation. 
Fig. 4.10. /hir/- native speaker's pronunciation.

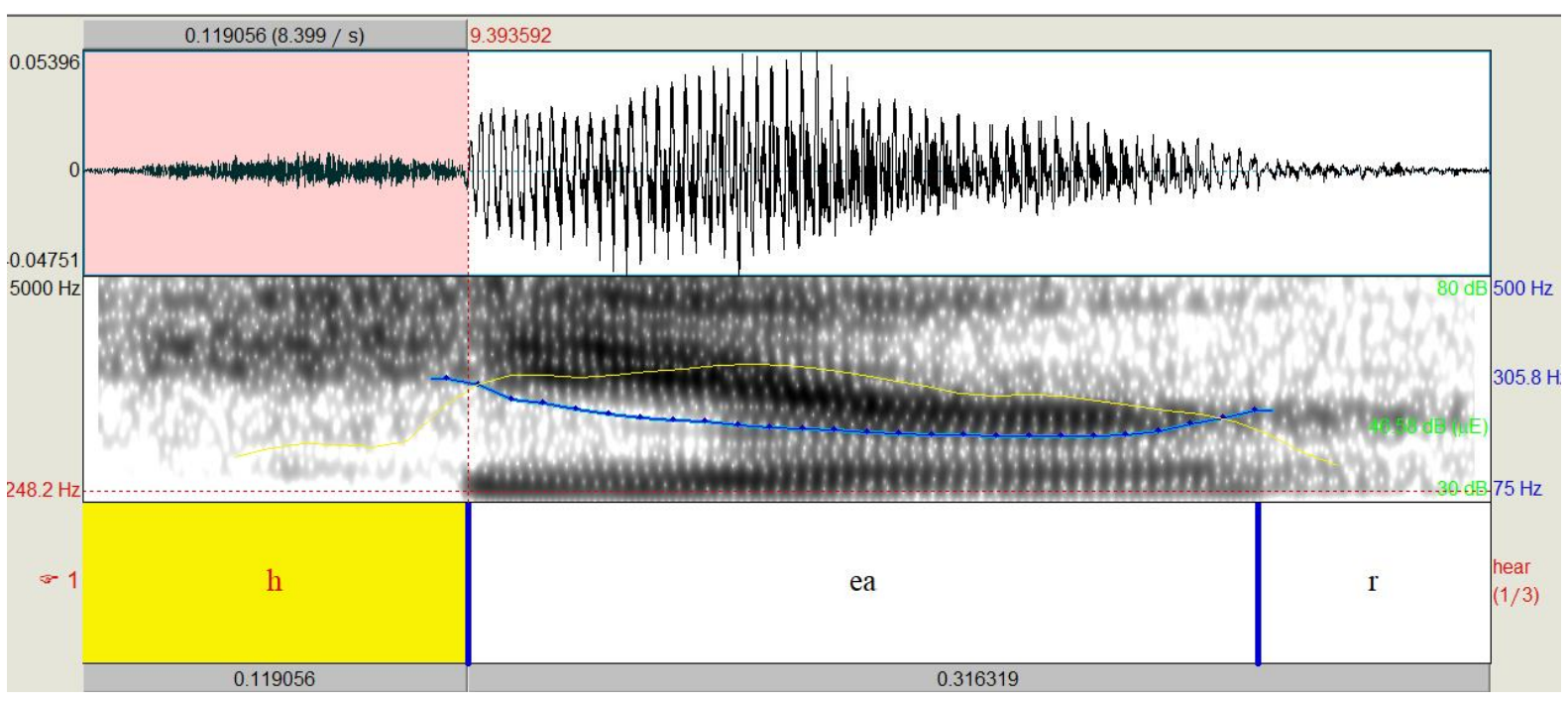

The above spectrum shows that there is a clear presence of $/ \mathrm{h} /$ at the beginning of this word which the Yoruba speaker did not pronounce. This indicates a clear case of transfer from Yoruba to English. I presume it may be easier for the Yoruba speakers to delete the $/ \mathrm{h} / \mathrm{than}$ trying to pronounce it since the sequence $/ \mathrm{hi} /$ is not in their mother tongue. The assumption here is that the Yoruba speaker cannot pronounce the sequence of $/ \mathrm{hi} /$ and because there is no contrast between zero and $/ \mathrm{h} /$ at this position in Yoruba, they transfer this rule into English by dropping the $/ \mathrm{h} /$ without thinking of changing the meaning of the word. The unrealized implication, however, is that 'hear' will be pronounced as 'ear', 'heat' will be pronounced as 'eat', etc.

Since it has been established that Yoruba speakers transfer the pronunciation of $/ \mathrm{h} /$ into English, it will not be out of place to the check the vowel-initial words in English as there is breathiness/frication, or a glottal stop before all word-initial vowels in Yoruba. This is to clarify that indeed there is the transfer of word-initial vowel pronunciation from Yoruba to English. The first step is to check the pronunciation of vowel initial-words in Yoruba in comparison to similar vowel-initial words in English, e.g., /E/ in egg and the word-initial / $/$ / in ege (cassava). 
Fig. 4.11./عge/ - cassava

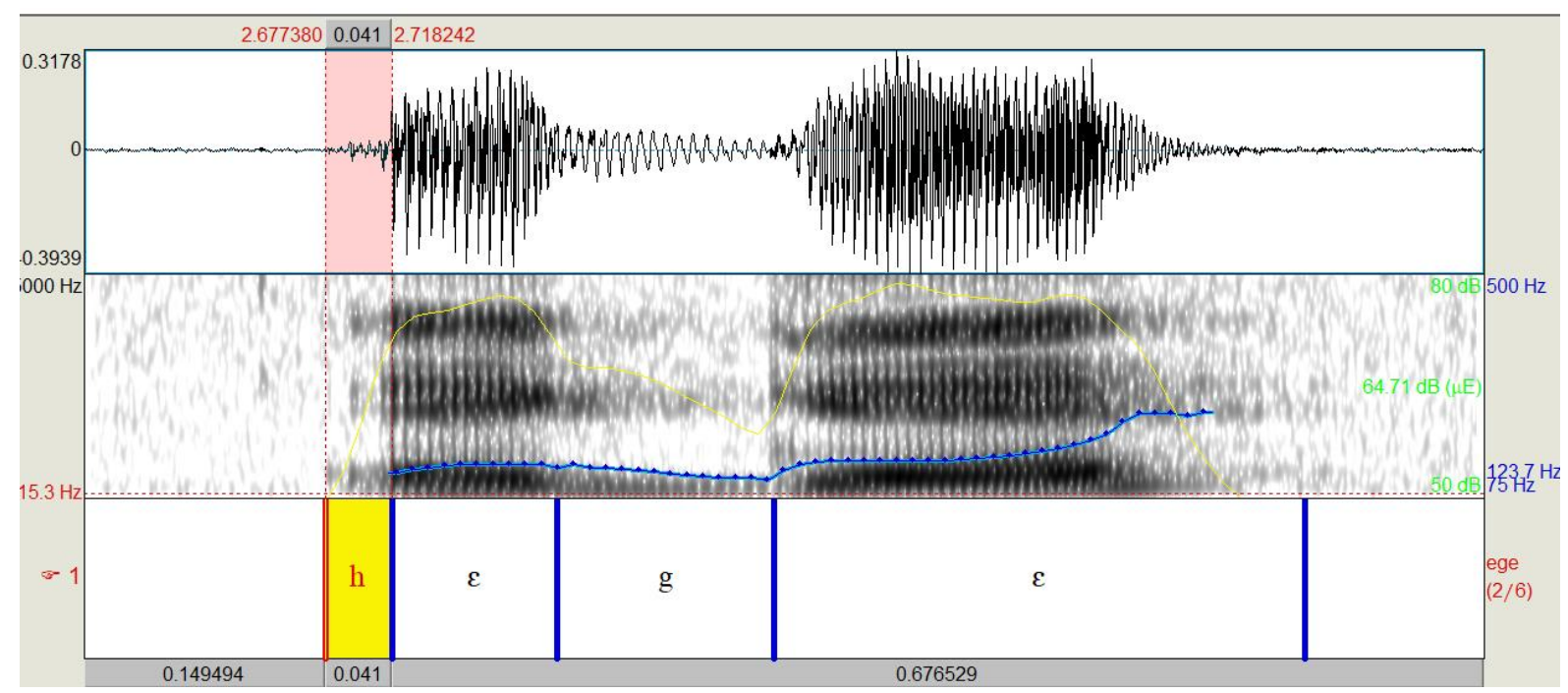

Fig. $4.12 / \varepsilon g /$

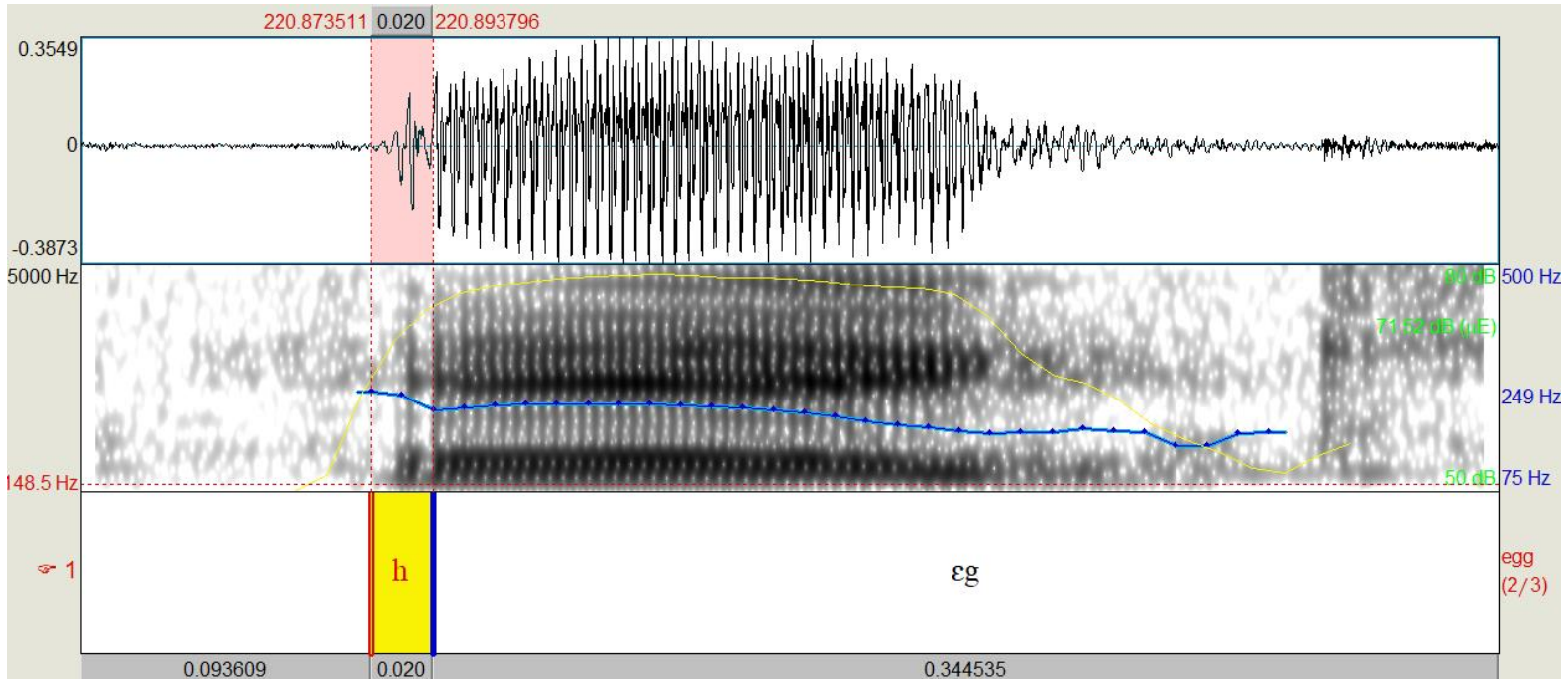

With the above illustration, there is a case of transfer of how word-initial vowels are pronounced in Yoruba to English, though the onset of 'egg' is pronounced with breathiness and the onset of 'ege' is pronounced with a glottal stop. Also, figure 4.11 shows a clear case of insertion of breathiness before the vowel-initial words in English. This can be verified by comparing the pronunciations in Yoruba to the native speaker's pronunciations. Examples are age, account, empty, etc. A clear picture can be seen below. 
Fig. 4.13. /Empti/ - native's speaker pronunciation

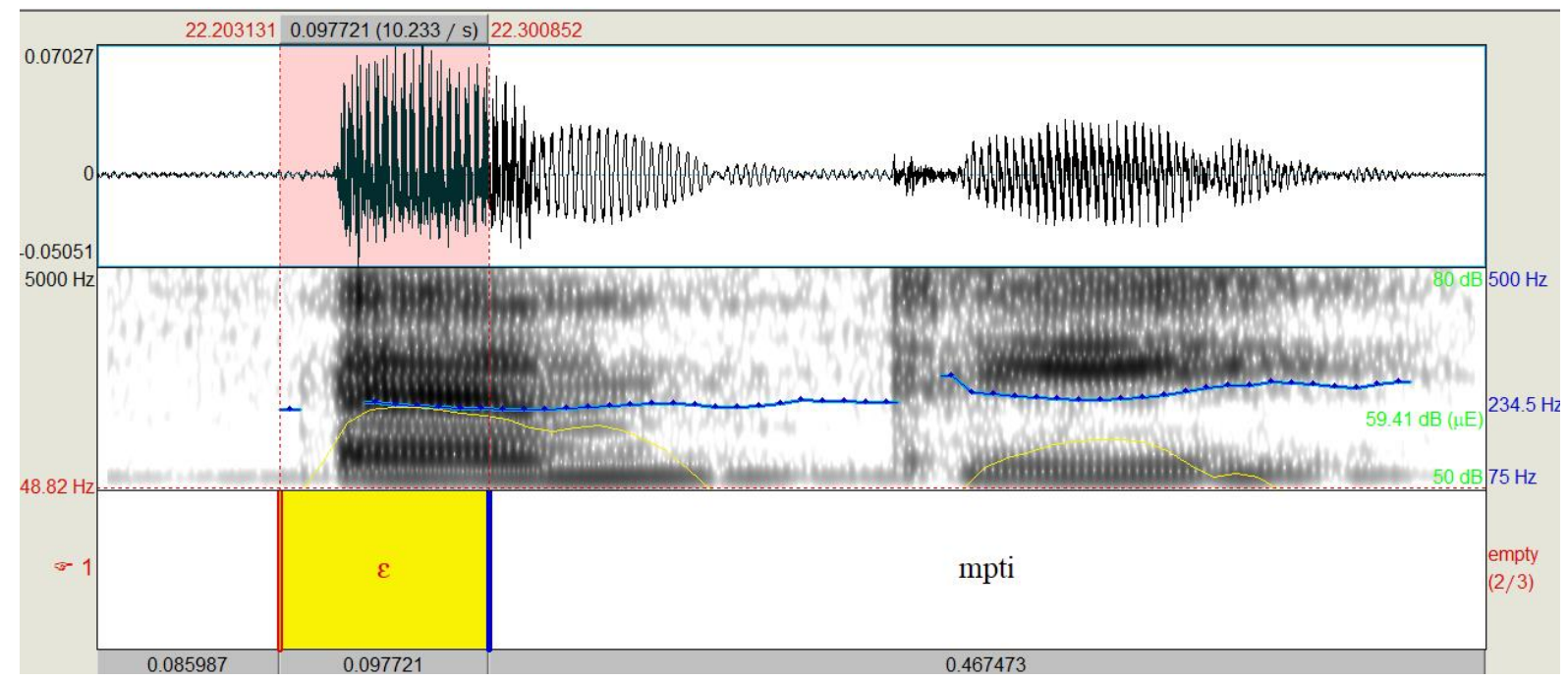

Fig. 4.14. /Empti/ - Yoruba speaker's pronunciation.

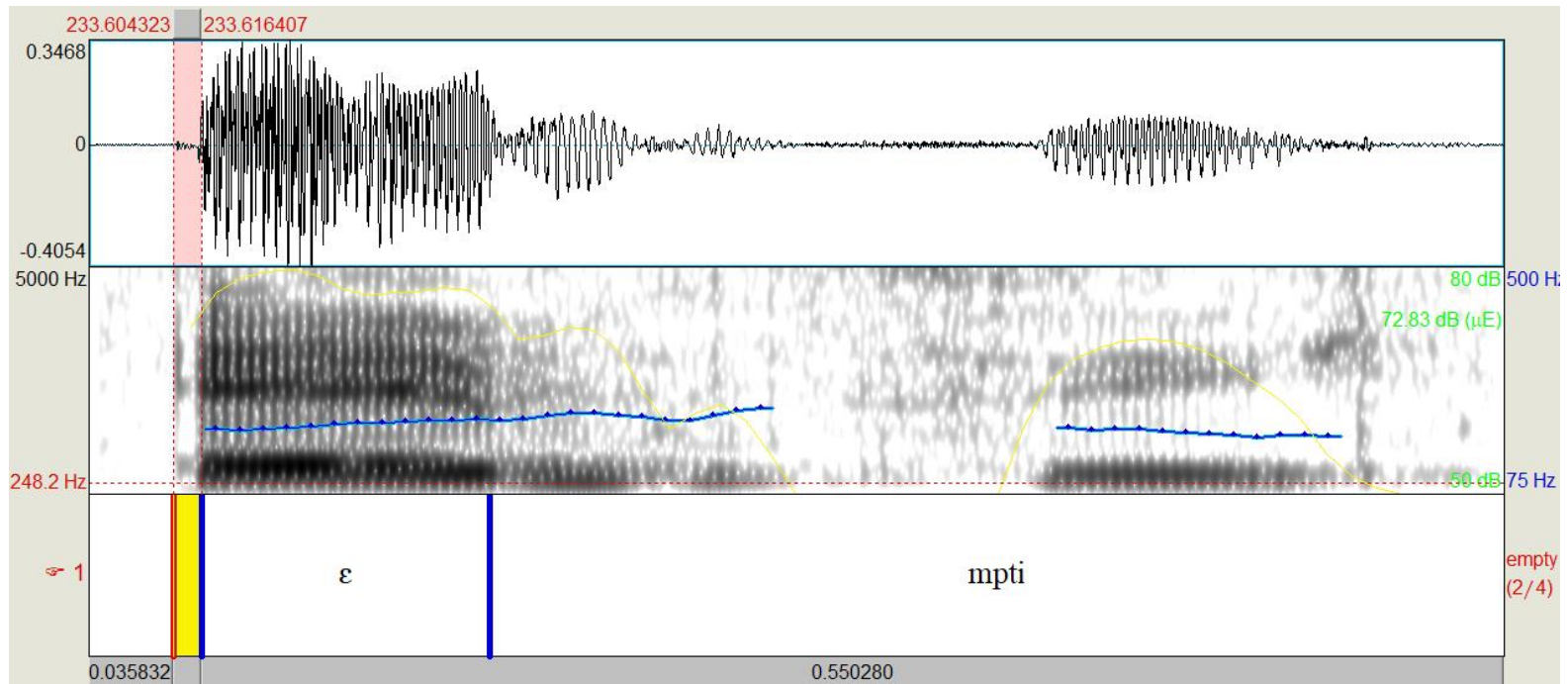

The example above shows a clear insertion of frication (the continuous black noise at the onset of the word-initial vowel) before the vowel by the Yoruba speaker. This indicates that the hypothesis of transfer is correct.

From the above analyses, it can be concluded that the Yoruba speakers transfer the attributes and characteristics of the Yoruba /h/ into English words, which leads to /h/ dropping 
and insertion. This conclusion is for Yoruba-English speakers in the third strata of Banjo's classification who are close to the Received Pronunciation (RP) but have not mastered the pronunciation of some sounds such as the voiceless glottal fricative $/ \mathrm{h} /$. Please note that not all Yoruba-English speakers transfer the characteristics of /h/ from Yoruba into English; especially those in the fourth strata of Banjo's analysis (on the levels of mother tongue influence on English). 


\section{CHAPTER 5}

\section{SUMMARY AND CONCLUSION}

\section{General summary}

In this research, I discussed the peculiarity of the Yoruba speakers of English language, the extent of mother tongue influence, and the classification of this influence based on the level of education of the Yoruba-English speakers. I also gave a brief history of $/ \mathrm{h} / \mathrm{dropping}$ phenomenon in native and second language learners in comparison with Yoruba speakers of the English language. I described what other phonologists have written about this phenomenon. I then raised the research questions and four hypotheses that could account for $/ \mathrm{h} / \mathrm{dropping}$ and insertion.

I further investigated the submissions between the two phonologists; Oyebade and Akinlabi, about the phonetic/phonological classification of $/ \mathrm{h} /$ in Yoruba. I used sixty-two Yoruba words as tokens of investigation and three participants to pronounce the words for analysis. I concluded that both phonologists were right about the Yoruba $/ \mathrm{h} / \mathrm{as}$ it is both a glottal approximant and a glottal fricative depending on the surrounding vowel and position of occurrence. However, I also found out that apart from the above proposal, the Yoruba $/ \mathrm{h} / \mathrm{can}$ also be realized as a glottal stop and sometimes as zero realization.

Furthermore, I realized that there is no sequence of $* /$ hi/ in Yoruba words. I also discovered that there are variant glottal realizations before all word-initial Yoruba vowels. Based on this information, I concluded that $/ \mathrm{h} / \mathrm{as}$ a word-initial consonant in Yoruba is at the verge of been lost in the language.

Also, I tried to decipher the reason for $/ \mathrm{h} /$ dropping and $/ \mathrm{h} /$ insertion by the Yoruba speakers of the English language. I compared twenty-three words pronounced by an American 
native speaker with that of the Yoruba participants. I discovered that the Yoruba-English speakers transfer the attributes of the Yoruba /h/ into English thus pronouncing the English /h/ as sometimes a fricative or breathiness, a stop and at other times an outright deletion. The hypothesized implication of this transfer is that the $/ \mathrm{h} /$ may be perceived by the native speaker as dropping when a zero or glottal stop is used instead of a fricative. Also, insertion may be perceived if there is an insertion of a glottal fricative or breathiness before a vowel-initial word. The important discovery in the analysis was that the Yoruba participants drop the $/ \mathrm{h} /$ in the 'hi' word sequence in English because there is no such sequence in Yoruba. This proved that it is a clear case of transfer from Yoruba to English as well as a clear case of /h/ dropping.

Finally, after close observation of the pronunciations of the native speaker and the Yoruba participants, I realized that there is a glottal presence before all the vowel-initial words (sometimes as stops, frication, or breathiness) pronounced by the Yoruba participants. The hypothesized implication is that; since breathiness or frication is not originally present in the native speaker's pronunciation at the onset of vowels, this could be perceived as insertion of $/ \mathrm{h} /$ even if it is a weak fricative.

\section{Hypotheses versus result}

The first hypothesis in chapter two was that there is no glottal fricative in Yoruba and thus the reason for /h/ dropping. This turned out to be a wrong hypothesis based on the results of the analysis in chapter three which showed that Yoruba has the glottal fricative though not phonemically contrastive from a zero, stop or breathiness.

The second hypothesis was that there may be two glottal sounds in Yoruba. The research showed that there are four variants of the glottal sound in Yoruba. Although, there is no adequate data in this research to adequately account for the position of occurrence of these variants; as such, a valid conclusion cannot be made. The transfer of the various realizations of 
the Yoruba /h/ into English words caused the /h/ dropping and insertion by Yoruba-English speaker.

The third hypothesis was that the distribution of $/ \mathrm{h} /$ in Yoruba is different from that of English /h/. The results show that the distributions are different as Yoruba uses variants of glottal realizations before all vowels, while English uses only the glottal stop; thus, causing /h/ insertion when breathiness or frication is used. Also, the presence or absence of the glottal sound at the word-initial position in Yoruba is not phonemically contrastive while in English it is contrastive as it could alter the meaning of the word. Finally, the sequence of 'hi' is not present in Yoruba while this sequence is present in English. This prompts the deletion of $/ \mathrm{h} / \mathrm{in}$ such sequences in English and thus the reason for perceived /h/ dropping by native speakers.

Finally, it is important to revisit the over-arching questions that I asked at the beginning of this research which are:

1. What characterizes the Yoruba $/ \mathrm{h} /$ and how does it differ from the English $/ \mathrm{h} /$.

The Yoruba /h/ differs from the English one because it has four variants: stop, fricative or breathy voice, glide and zero. These variants can be used interchangeably without constraints or causing phonemic contrast. Also, the Yoruba /h/does not occur before the high front /i/ at the word-initial position. On the other hand, the English /h/ is underlyingly a fricative with the glottal stop [?] as a variant. The glottal stop is used at phrase boundary or before syllable-initial vowels. This variant cannot be used interchangeably with the fricative as it causes phonemic contrast. The English /h/ occurs before the high front vowel /i/ at the word-initial position.

2. If there is a difference between the Yoruba $/ \mathrm{h} /$ and the English $/ \mathrm{h} /$, could it adequately account for the /h/ dropping and insertion perceived by the native English speakers? 
The differences between the Yoruba /h/ and the English /h/ accounted for the perceived $/ \mathrm{h} /$ dropping and insertion as there is the transfer of the attributes of the Yoruba /h/ into English words. The implications of this transfer are:

1. The insertion of frication or breathiness before a vowel-initial word in English will be perceived as insertion. This is because a glottal stop is expected in this position.

2. The insertion of a glottal stop or a zero realization in the place of a fricative will be perceived as deletion or $/ \mathrm{h} /$ dropping e.g. the deletion of $/ \mathrm{h} /$ in the 'hi' sequence in an English word will be perceived as /h/ dropping.

It is worthy to note that the insertion of a glottal stop before a vowel-initial word in English will not be perceived as insertion as this is the actual pronunciation by the native speaker.

\section{Conclusion / further research}

The conclusion that can be inferred from the summary and research result is that the Yoruba glottal sound is unique and there is evidence of transfer of this uniqueness from Yoruba to the English language, thus causing the /h/ dropping and insertion.

This study also shows that the case of the Yoruba-English speakers is different from the French learners discussed in chapter two, as they are not hypercorrecting any error but simply transferring the variants of the Yoruba $/ \mathrm{h} /$ into English.

An in-depth study of perception by the native speaker to the pronunciations of the Yoruba-English speaker $/ \mathrm{h} /$ was not included in this research. This is an interesting topic that will be good for follow-up research.

Also, the position of occurrence of the glottal variants in Yoruba is an important aspect that will be good for further research because this will help to decipher where and when the 
Yoruba-English speaker uses a fricative, a stop, and breathiness in English words and which of the variants is used in the else-where condition.

Finally, the results from this research show that the Yoruba /h/, although quite different and unique, is at the verge of being lost from the standard Yoruba. 


\section{References}

Adedun, E. A. (n.d). The Future of Nigerian English, Department of English, University of Lagos, Akoka - Yaba Lagos, Nigeria. Retrieved from http://mtu.edu.ng/mtu/oer/journals/252-the\%20future\%20of\%20nigerian\%20english\%20final.pdf

Akinlabi, A. (1982). The sound system of Yoruba. In Lawal, N.S., Sadiku, M.N.O., \& Dopamu, A. (Eds). Understanding life and culture. Africa World Press Inc., pg. 453-468

Akinlabi, A. (199I). Supraglottal deletion in Yoruba glides. In Proceedings of the Tenth West Coast Conference on Formal Linguistics. pg. 13-26 Stanford, CA: Center for the Study of Language and Information.

Akinlabí, A. (2004). The Sound System of Yorùbá. Understanding Yorùbá Life and Culture pg.453-468. Africa World Press, Trenton, NJ, 8607.

Bamgbose, A. (1966). A Grammar of Yoruba. Cambridge: The Cambridge University Press.

Biobaku, S. (1958). The pattern of Yoruba history. Africa South, 2(2). Retrieved from http://disa.ukzn.ac.za/sites/default/files/pdf_files/asjan58.14.pdf

Boersma, P. \& Weenink, D. (2019). Praat: doing phonetics by computer [Computer program]. Version 6.0.49 retrieved 2 March 2019 Retrieved from http://www.praat.org/

Dada, S.A. (2007). Language Contact and Language Conflict: The case of Yoruba-English bilinguals. Kansas Working Papers in Linguistics 29 pg.85-113.

Eme, C. A., \& Uba, E. D. (2016). A Contrastive Study of the Phonology of Igbo and Yoruba UJAH: Unizik Journal of Arts and Humanities, 17(1), 65-84.

Ethnologue of Languages of the World. 22nd edition. Retrieved from https://www.ethnologue.com/language/yor

GAS, S. and Selinker, L. (2008). Second language acquisition: an introductory course. 3rd Ed. Hillsdale, New Jersey: Lawrence Erlbaum. 
Gut, U. B. (2008). Nigerian English. Phonology: Varieties of English, 4, pg.35-54.

Kenstowicz, M., \& Suchato, A. (2006). Issues in loanword adaptation: A case study from Thai. Lingua, 116(7), 921-949.

Muhammad, H.A., Ya'u S., Aliyu, U.I., Hassan, M. (2018). Teaching and Learning English Language in Nigerian Schools: Importance and Challenges. Teacher Education and Curriculum Studies. Vol. 3, No. 1, pg. 10-13.

Olaniyi, O.K. \& Ekerete J.U. (2013). Nigerian Accents of English in the Context of World Englishes. World Journal of English Language: Vol. 3, No. 1; 2013.

Olaniyi, O. K. (2014). The taxonomy of Nigerian varieties of spoken English. International Journal of English and Literature, 5(9), 232 - 240.

Oyebade, F.O. (1992). Yoruba Phonology. In Ore Yusuf (ed.) Basic linguistics for Nigerian languages teachers. Port Harcourt. M \& J Grand Orbit Communications Ltd. and Emhai Press. pg.221-239.

Paradis, C. \& Darlene, L. (2001). Guttural deletion in loanwords. Phonology,18.2: pg. 255-300

Paul, J. \& Walcir C. (2008) Francophone ESL Learners and [h]-Epenthesis. Concordia: Working Papers in Applied Linguistics, 1, 2008.

Picard, M. (1987). An introduction to the comparative phonetics of English and French in North America (Vol. 7). John Benjamins Publishing.

Pierrehumbert, J., \& Talkin, D. (1992). Lenition of /h/ and glottal stop. Papers in Laboratory Phonology II: Gesture, Segment, Prosody. Docherty G., \& Ladd D. R., (eds.), pg.90117. Cambridge: Cambridge University Press.

Rotimi, O.O. (2014). Aspects of Connected Speech Processes in Nigerian English. SAGE: October-December 2014: pg. 1-6. 
Ugorji, C. (2010). Nigerian English Phonology: A preference grammar. 21, linguistik, pg.352. Frankfurt am Main: Lang.

Wells, J.C. (1982). Accents of English: The British Isles. Vol. 2, Cambridge: Cambridge UP.

Yoruba people and culture. African Studies Institute, University of Georgia. Retrieved from 


\section{Appendix 1}

\begin{tabular}{|c|c|c|}
\hline & Initial Glottal sound & Glottal realization \\
\hline 1 & /عyĩ/ & glottal stop \\
\hline 2 & /Ege/ & glottal fricative \\
\hline 3 & /عri/ & glottal stop \\
\hline 4 & /eeri/ & glottal stop \\
\hline 5 & /Egã/ & glottal stop \\
\hline 6 & /ada/ & glottal fricative \\
\hline 7 & /aake/ & glottal fricative \\
\hline 8 & /eemi/ & glottal stop \\
\hline 9 & /Egba/ & glottal stop \\
\hline 10 & /igbagbo/ & glottal stop \\
\hline 11 & /igba/ & glottal stop \\
\hline 12 & /ede/ & glottal fricative \\
\hline 13 & /imã/ & glottal stop \\
\hline 14 & /idi/ & glottal fricative \\
\hline 15 & /aso/ & glottal fricative \\
\hline 16 & /ibadi/ & glottal stop \\
\hline 17 & /igi/ & glottal stop \\
\hline 18 & /Jdũ// & glottal stop \\
\hline 19 & /osã/ & glottal stop \\
\hline 20 & /aadũ/ & glottal fricative \\
\hline 21 & /amĩ/ & glottal stop \\
\hline 22 & /aamĩ/ & glottal stop \\
\hline 23 & /iwe/ & glottal stop \\
\hline
\end{tabular}




\begin{tabular}{|c|c|c|}
\hline 24 & /Ese/ & glottal fricative \\
\hline 25 & /eese/ & glottal stop \\
\hline 26 & /ikpako/ & glottal stop \\
\hline 27 & /aarĩ/ & glottal fricative \\
\hline 28 & /orĩ/ & glottal fricative \\
\hline 29 & /ikã/ & glottal stop \\
\hline 30 & /aini/ & glottal stop \\
\hline 31 & /arã/ & glottal stop \\
\hline 32 & /ho/ & glottal stop \\
\hline 33 & $/ \mathrm{h} \mathrm{h} /$ & glottal stop \\
\hline 34 & /hã/ - grip & glottal stop \\
\hline 35 & /hã/ - show & glottal stop \\
\hline 36 & /ha/ & glottal stop \\
\hline 37 & /he/ & glottal stop \\
\hline 38 & /heĩ/ & glottal stop \\
\hline 39 & /hũ/ & glottal stop \\
\hline 40 & /ho/ - scratch & glottal stop \\
\hline 41 & /ho/ - run & glottal stop \\
\hline 42 & /hãrũ/ & glottal stop \\
\hline 43 & /ho/ & glottal stop \\
\hline 44 & /عhĩ/ & glottal stop \\
\hline 45 & /iho/ & - \\
\hline 46 & /ohũ/ & glottal stop \\
\hline 47 & /iha/ & glottal stop \\
\hline 48 & /Ehonu/ & glottal stop \\
\hline 49 & /ehoro/ & glottal stop \\
\hline
\end{tabular}




\begin{tabular}{|l|l|l|}
\hline 50 & /ahere/ & glottal stop \\
\hline $51 /$ & /aheso/ & glottal fricative \\
\hline 52 & /ihamo/ & glottal stop \\
\hline 53 & /ihĩ/ & glottal fricative \\
\hline 54 & /ahusa/ & glottal fricative \\
\hline 55 & /iho/ & glottal stop \\
\hline 56 & /ihoho/ & glottal stop \\
\hline 57 & /ahoro/ & glottal stop \\
\hline 58 & /idahoro/ & glottal stop \\
\hline 59 & /idahũ/ & glottal glide \\
\hline 60 & /Elahã/ & glottal stop \\
\hline 61 & /ihamora/ & glottal fricative \\
\hline
\end{tabular}


Appendix 2

\begin{tabular}{|c|c|c|}
\hline & Medial glottal sound & Glottal realization \\
\hline 1 & /عhĩ/ & glottal glide \\
\hline 2 & /iho/ & glottal glide \\
\hline 3 & /ohũ/ & glottal glide \\
\hline 4 & /iha/ & glottal glide \\
\hline 5 & /Ehonu/ & glottal glide \\
\hline 6 & /ehoro/ & glottal glide \\
\hline 7 & /ahere/ & glottal glide \\
\hline 8 & /aheso/ & glottal glide \\
\hline 9 & /ihamo/ & glottal glide \\
\hline 10 & /ihĩ/ & glottal glide \\
\hline 11 & /ahusa/ & glottal glide \\
\hline 12 & /iho/ & glottal glide \\
\hline 13 & /ihoho/ & glottal glide \\
\hline 14 & /ahoro/ & glottal glide \\
\hline 15 & /idahoro/ & glottal glide \\
\hline 16 & /idahũ/ & glottal glide \\
\hline 18 & /gbehэ/ & glottal glide \\
\hline 19 & /mehe/ & glottal glide \\
\hline 20 & /Elahã/ & glottal glide \\
\hline 21 & /ihamora/ & glottal glide \\
\hline
\end{tabular}




\section{Appendix 3}

\section{ENGLISH WORDS}

Head

Hit

House

Half

Health

Hide

Hard

Heat

Hear

Horn

Hurt

Hut

Egg

Aero-plane

Account

Encourage

Include

Access
Initial

Age

Empty

Offer

Occupy

Uncle

Obesity

Suburb

Mishap

Consult

Exhort

Insult 


\section{Appendix 4}

YORUBA/ ENGLISH

Eyin- egg

Ege- cassava

Eri- testimony

Eeri- dirt

Egan- reproach

Ada- cutlass

Aake- axe

Eemi- breath

Egba- a tribe of Yoruba

Igbagbo- faith

Igba- garden egg

Ede- language

Imon- knowledge

Idi- buttocks

Aso- cloth

Ibadi- waist

Igi- tree

Odun- year

Osan- orange

Aadun- corn meal

Amin- amen

Aamin- amen

Iwe- book

Eese- why

Ese- $\quad \sin$

Ipako- back of the head

Aarin- middle

\section{YORUBA/ ENGLISH}

ho- shout

ha- scratch

han- screech

han- show

he- find

hein- yes

hain- yes

hun- weave (basket)

ho- scratch (throat)

ho- run

hanrun- snore

ho- boil (water)

ehin- back

iho- hole

ohun- voice

iha- side

ehonu- protest/ grievance

ehoro- rabbit

ahere- shelter/hut

ihamo- confinement

ihin- here

ahusa- walnut

iho- horn (of goat)

ihoho- naked

ahoro- empty

idaharo- empty

idahun-answer 
Orin- $\quad$ song

Ikan- garden egg

Aran- day dreaming

Aini- lack gbeho- escape

mehe- interruption

elahan- expatiate

ihamora- armour 